\title{
Structure, Activity and Function of a Singing CPG Interneuron Controlling Cricket Species-Specific Acoustic Signaling
}

\author{
(DPedro F. Jacob ${ }^{1,2}$ and $\odot$ Berthold Hedwig $^{1}$ \\ ${ }^{1}$ Department of Zoology, University of Cambridge, Cambridge CB2 3EJ, United Kingdom and ${ }^{2}$ Champalimaud Neuroscience Programme, Champalimaud \\ Centre for the Unknown, Lisbon, Portugal
}

The evolution of species-specific song patterns is a driving force in the speciation of acoustic communicating insects. It must be closely linked to adaptations of the neuronal network controlling the underlying singing motor activity. What are the cellular and network properties that allow generating different songs? In five cricket species, we analyzed the structure and activity of the identified abdominal ascending opener interneuron, a homologous key component of the singing central pattern generator. The structure of the interneuron, based on the position of the cell body, ascending axon, dendritic arborization pattern, and dye coupling, is highly similar across species. The neuron's spike activity shows a tight coupling to the singing motor activity. In all species, current injection into the interneuron drives artificial song patterns, highlighting the key functional role of this neuron. However, the pattern of the membrane depolarization during singing, the fine dendritic and axonal ramifications, and the number of dye-coupled neurons indicate species-specific adaptations of the neuronal network that might be closely linked to the evolution of species-specific singing.

Key words: activity patterns; evolutionary neurobiology; neuronal mechanisms; singing CPG; species-specific behavior

\section{Significance Statement}

A fundamental question in evolutionary neuroscience is how species-specific behaviors arise in closely related species. We demonstrate behavioral, neurophysiological, and morphological evidence for homology of one key identified interneuron of the singing central pattern generator in five cricket species. Across-species differences of this interneuron are also observed, which might be important to the generation of the species-specific song patterns. This work offers a comprehensive and detailed comparative analysis addressing the neuronal basis of species-specific behavior.

\section{Introduction}

Behavioral changes in signaling for mate attraction and courtship are very important in speciation processes (Muller, 1939; Kaneshiro, 1980; Endler and Basolo, 1998; Boughman, 2002; Ritchie, 2007).

Received May 7, 2018; revised Sept. 22, 2018; accepted Sept. 25, 2018.

Author contributions: P.F.J. wrote the first draft of the paper; P.F.J. and B.H. edited the paper; P.F.J. and B.H. designed research; P.F.J. performed research; P.F.J. analyzed data; P.F.J. wrote the paper.

P.F.J. was supported by the Fundação para a Ciência e a Tecnologia, Portugal (Grant SFRH/BD/51901/2012) and the equipment used in this research was funded by the Biotechnology and Biological Sciences Research Council (Grant BB/G018723/1). We thank Gerald Pollack (McGill University) for providing G. assimilis and G. rubens eggs; Nathan Bailey (University of St. Andrews) and his team (Tony Ly, Suzanne Vardy, Peter Moran, and Katherine Holmes) for eggs of T. commodus and T. oceanicus, which were used to establish the populations used in this study; Nigel Hall for technical support in rearing the crickets; and Steve M. Rogers for comments on the manuscript.

The authors declare no competing financial interests.

P.F. Jacob's present address: Centre for Neural Circuits and Behaviour, The University of Oxford, Tinsley Building, Mansfield Road, Oxford OX1 3SR, United Kingdom.

Correspondence should be addressed to Berthold Hedwig: Department of Zoology, University of Cambridge, Downing Street, Cambridge CB2 3EJ, United Kingdom. E-mail: bh202@cam.ac.uk.

https://doi.org/10.1523/JNEUROSCl.1109-18.2018

Copyright $\odot 2019$ the authors $\quad 0270-6474 / 19 / 390096-16 \$ 15.00 / 0$
Changes in species-specific behavior can be achieved by altering the signal type; for example, converting between sound and vibration (ter Hofstede et al., 2015) and modifications of peripheral structures while keeping the motor patterns (Elsner and Wasser, 1995; Vedenina et al., 2012) or adaptations at the level of the nervous system that lead to different motor patterns (Katz and Harris-Warrick, 1999). Comparing identified neurons and network properties in closely related species that just differ in the motor patterns used to generate sexual communication signals (Arbas et al., 1991; Crews, 1997; Katz and Harris-Warrick, 1999; Ritchie, 2007) provides the chance to gain insights into evolutionary specializations of neural circuits.

Two of the most impressive examples of species-specific motor patterns separating species occur in acoustically communicating insects on Hawaii within the "picture-winged" Drosophila species group (Hoy et al., 1988; Hoikkala et al., 1989) and the crickets of the genus Laupala (Shaw, 1996; Mendelson and Shaw, 2002). In both groups, sister species may be morphologically identical, but the temporal patterns of the male song, which are 
closely linked to the female signal preferences, drive speciation (Hoikkala et al., 1994; Mendelson and Shaw, 2005). The temporal structure of the signal patterns is under the control of the nervous system, by the activity of central pattern generators (CPGs) (Capranica, 1992; Chagnaud et al., 2011; Schöneich and Hedwig, 2012). Recently, the neuronal basis for the singing CPG in Drosophila (Clyne and Miesenböck, 2008; von Philipsborn et al., 2011, 2014, Shirangi et al., 2013; Ding et al., 2016) has been explored using a genetic approach. Crickets, however, offer advantages given the detailed knowledge of their song circuitry and its electrophysiological properties (Bentley, 1969; Hennig, 1989; Kutsch and Huber, 1989, 1990; Schöneich et al., 2011; Schöneich and Hedwig, 2012). Furthermore, the specific genetic tools in Drosophila that allow labeling of single neurons are for the most part limited to one species.

Crickets display species-specific song patterns that are identi$\mathrm{cal}$ in their role as a far-field communication signal to attract females. This supports the homology of the acoustic behavior in crickets (Alexander, 1962; Otte, 1992), offering the opportunity to identify and compare homologous neurons across species to gain insights into the neural basis of signaling behavior and its species-specific neural specializations during evolution.

Male crickets sing by rhythmically opening and closing their front wings. This movement is generated by the activity of wingopener and wing-closer muscles and motoneurons and their activity mirrors the species-specific pulse pattern in fictive singing (Kutsch and Huber, 1989; Poulet and Hedwig, 2003). Songs can be described by the carrier frequency and the pulse pattern. Within the temporal domain, each closing movement generates a short sound pulse and, in a song, these are organized in a speciesspecific manner in groups or sequences of pulses: chirps and trills. Although the wing size and shape can affect sound production (Montealegre- $Z$ et al., 2011), these parameters are only weakly correlated with calling song structure (Blankers et al., 2017), pointing to the importance of the temporal parameters that are under control of the CPG.

Therefore, to understand how species-specific behaviors arise in closely related species, we analyzed the abdominal ascending opener interneuron (A3-AO), an identified singing CPG interneuron, in bi-spotted field crickets, Gryllus bimaculatus (Schöneich and Hedwig, 2011, 2012), across different species. We compared the structure, activity patterns, and effect on singing motor pattern generation of $\mathrm{A} 3-\mathrm{AO}$ in five cricket species.

\section{Materials and Methods}

Animals. We used male crickets of Gryllus bimaculatus DeGeer, Gryllus assimilis Fabricius, Gryllus rubens Scudder, Teleogryllus oceanicus Le Guillou, and Teleogryllus commodus Walker. Males were kept individually in plastic containers at $26-28^{\circ} \mathrm{C}$ with a $12 \mathrm{~h}$ light/dark cycle and were used from 7-21 d after ecdysis. A mixture of protein-rich food and water was provided ad libitum. Experiments were performed at $23-24^{\circ} \mathrm{C}$ and complied with the principles of laboratory animal care (ASAB Ethics Committee, 1997).

Song recordings. Songs of individual males of each species were recorded for two to three nights with a PC microphone (Omni type; Maplin Electronics) at a sampling rate of $48 \mathrm{kHz}$ using Cool Edit 2000 software (Syntrillium Software). See Jacob and Hedwig (2016) for details.

Dissection and pharmacological brain stimulation. Before experiments, crickets were cooled down and placed dorsal side up on a Plasticine block by restraining all legs with metal clamps. The head was waxed to a metal holder and opened to access the brain. We accessed the central nervous system by a dorsal midline incision along the abdomen and thorax and peripheral nerves to the thoracic and abdominal ganglia were cut, except for the mesothoracic wing nerve $3 \mathrm{~A}$ (meso-Nv3A) and the cercal nerves. See Jacob and Hedwig (2015) for details.
Exposed nervous tissue was rinsed with saline containing the following (in mmol $1^{-1}$ ): $\mathrm{NaCl} 140, \mathrm{KCl} 10, \mathrm{CaCl}_{2} 7, \mathrm{NaHCO}_{3} 8, \mathrm{MgCl}_{2} 1$, TES 5, and D-trehalose dehydrate 4 adjusted to $\mathrm{pH}$ 7.4. To elicit fictive singing, glass capillaries filled with either eserine salicylate $\left(10^{-2} \mathrm{~mol} \mathrm{l}^{-1}\right)$ for Gryllus or a mixture of eserine salicylate $\left(10^{-2} \mathrm{~mol} \mathrm{l}^{-1}\right)$ and nicotine $\left(10^{-3} \mathrm{~mol} \mathrm{l}^{-1}\right.$; Sigma-Aldrich) for Teleogryllus in saline were inserted into the ventral protocerebrum and the solution was pressure injected (Pneumatic PicoPump PV820, WPI). See Wenzel and Hedwig (1999) and Schöneich and Hedwig (2012) for details. The efficacy of pharmacological stimulation in Gryllus species was $80 \%$; in Teleogryllus, $50 \%$ of males generated a mixture of all song types and $24 \%$ of males generated a pure calling song $(N=34)$.

The singing motor pattern was recorded from the meso-Nv3A (for details, see Jacob and Hedwig, 2015), which contains the axons of the front wing opener and closer motoneurons (Kutsch and Huber 1989; Poulet and Hedwig, 2003). During singing, the nerve recording reliably showed the rhythmically alternating spike activity of these two types of motoneurons. We identified the opener motoneurons as the one that were always activated first and followed by the activity of the closer motoneurons. We used a double-hook electrode made from $100 \mu \mathrm{m}$ platinum wire and amplified the signal with a differential AC amplifier (Model 1700; A-M Systems).

Intracellular recordings of the ascending opener interneuron in the A3 abdominal ganglion. The $\mathrm{A} 3$ ganglion was stabilized between a stainless steel platform and a tungsten ring. Microcapillaries were pulled (DMZUniversal Puller, Zeitz Instruments) from thick-walled borosilicate glass tubes (ID $0.58 \mathrm{~mm}$, OD $1.0 \mathrm{~mm}$; Hilgenberg). Intracellular recordings were made in bridge mode (SEC10-05LX amplifier; NPI) and sampled at $40 \mathrm{kHz}$ per channel (Micro1401 mk II, CED). A3-AO interneurons were recorded at the midline in the posterior region of the $\mathrm{A} 3$ ganglion at a depth of 25-40 $\mu \mathrm{m}$ and along the main neurite at a depth of 70-100 $\mu \mathrm{m}$ as measured with an Absolute Digimatic Depth Gauge (Mitutoyo UK) attached to the micromanipulator.

The neurons identified in this work were considered to belong to the singing CPG according to criteria established by Marder and Calabrese (1996), which are as follows: (1) the neurons are active in time with the singing motor pattern; (2) the neurons initiate, terminate, or change the expression of the ongoing singing motor activity; and (3) the neurons have direct or oligosynaptic connections with the relevant motoneurons.

Neuron morphology. Fluorescent dyes were iontophoretically injected into recorded neurons by constant hyperpolarizing current injection [0.5-5 nA, up to $20 \mathrm{~min}$; for $0.5 \%$ Alexa Fluor 568 hydrazide sodium salt, Invitrogen, or $1 \%$ Lucifer yellow (LY), Sigma-Aldrich] or by depolarizing pulses (2-3 nA, $200 \mathrm{~ms}$ duration, $3 \mathrm{~Hz}$, up to $60 \mathrm{~min}$; for 2-4\% neurobiotin, Vector Laboratories). Histological processing followed conventional protocols (Schöneich et al., 2011; Schöneich and Hedwig, 2012). The whole-mount preparations were scanned with a confocal laserscanning microscope (Leica SP5). The morphology of neurons was reconstructed from the confocal image stacks using the Simple Neurite Tracer plugin in ImageJ. All neurons presented here were stained with neurobiotin unless otherwise stated. Because the neurons are dye coupled, a short 10 min protocol of neurobiotin injection was performed, which was sufficient to stain the neuron up to T2, but not the dyecoupled neuron. The images obtained were compared with stainings obtained with Alexa Fluor 568 and LY (data not shown), which are less reliable in showing dye coupling between neurons when they are performed for a few minutes. "Ipsilateral" and "contralateral" are used in relation to the neuron's cell body. We will refer to the A3-AO homologues of the species as $\mathrm{A} 3-\mathrm{AO}_{\text {species }}$; for example, the $\mathrm{A} 3-\mathrm{AO}$ in $\mathrm{G} . \mathrm{bi}$ maculatus will be labeled $\mathrm{A} 3-\mathrm{AO}_{\text {bimac }}$ and in G. assimilis as $\mathrm{A} 3-\mathrm{AO}_{\text {assim }}$.

Data analysis. Neurophysiological recordings were analyzed with CED Spike2 software and with NEUROLAB (Knepper and Hedwig, 1997). In case of song recordings for each male, three 10 min time windows with stable singing activity at the beginning, middle, and end of one overnight singing period were chosen and the mean and SD $(\bar{x} \pm S D)$ of song parameters were calculated using the burst analysis feature of Spike2 (Jacob and Hedwig, 2016).

For analysis of A3-AO activity, the onsets of wing-opener and wingcloser motoneuron activity were used as temporal references. In the fic- 


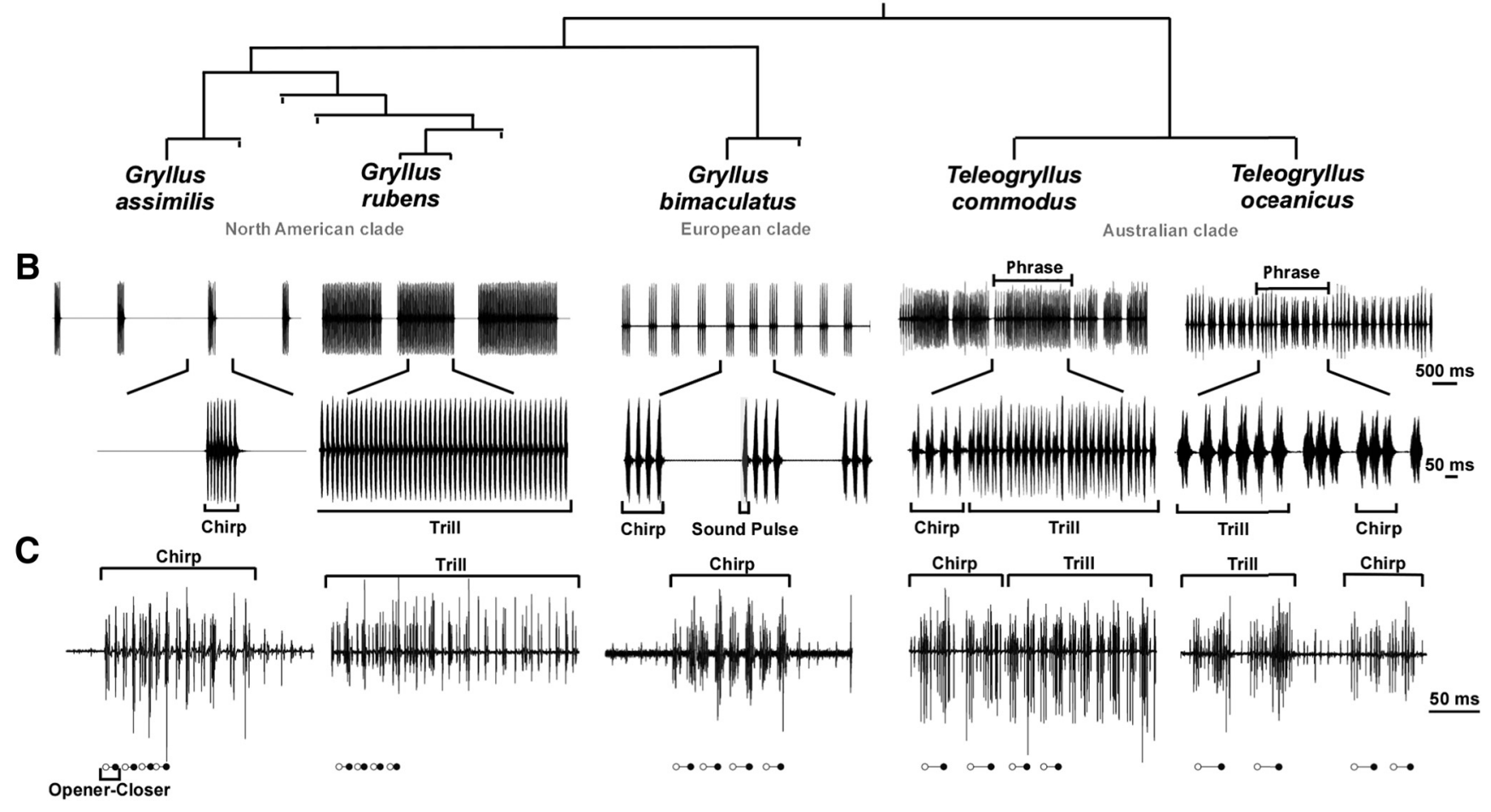

Figure 1. A, Phylogenetic relationship of cricket species studied and their natural and fictive calling song patterns. Shown is the simplified cricket phylogenetic tree derived from Huang et al. (2000), representing the species used in this study. B, Sound recordings of the male calling songs with low (top) and high (bottom) temporal resolution. C, Extracellular recordings of the meso-Nv3A during fictive singing in the species studied. The wing-opener motoneuron activity is represented by open circles and the wing-closer motoneuron activity by closed circles. The paired wing-opener and wing-closer activity represents one pulse period; that is, the silent pulse interval and the pulse. In each species, the motor pattern of the fictive calling song reflects accurately the pattern of the natural calling song.

tive singing motor pattern, the pulse period corresponds to the time between the first spike of two consecutive wing-closer bursts. The start of the ramp depolarization before singing episodes was established as the moment when the membrane potential differed by 1 SD from the mean resting amplitude for $10 \mathrm{~ms}$ subsequently. The duration of the ramp was measured from its start to the moment when the rising phase of the burst depolarization of the $\mathrm{A} 3-\mathrm{AO}$ started; the final amplitude of the ramp was also measured at this point. The rising phase was identified visually by the much faster membrane potential change of the neuron.

During the rhythmic membrane potential changes, two features of the neuronal activity were measured: (1) the time from the peak of the hyperpolarization to the moment of transition (H-to-T) and (2) the time from the transition to the first spike of the burst depolarization (T-to-S). The transition moment was identified based on the speed of the rising membrane potential of the $\mathrm{A} 3-\mathrm{AO}$, the arrowheads in the figures mark the transition point. Given the duration of the T-to-S interval and the corresponding change in the depolarization, we calculated the rate of membrane potential change (in millivolts per millisecond) at the start of a spike burst.

For the rebound depolarization after a hyperpolarization induced by current injection, the latency was measured between the end of the hyperpolarization current pulse and the occurrence of the first spike of the rebound. The amplitude of the rebound was measured between the resting membrane potential and the peak of the depolarization.

Normally distributed data are given as $\bar{x} \pm S D$; when normality tests failed, the median and interquartile range (IQR: $25^{\text {th }}$ percentile/ $75^{\text {th }}$ percentile) is presented. In pooled datasets, each contributing animal is equally represented (where $N$ is the number of animals and $n$ is the number of stimulations or events). For statistical analysis, we used GraphPad Prism 6 software.

\section{Results}

Five cricket species were chosen due to their very distinctive calling song patterns, with pulses grouped in chirps or complex songs with chirps and trills (Fig. 1). They were selected from the genus Teleogryllus or Gryllus, with Gryllus species from the European or North American clade (Huang et al., 2000; Fig. 1A). Recordings of the calling songs are shown in Figure $1 B$.

In the calling songs of G. bimaculatus and G. assimilis, sound pulses with a constant pulse rate are grouped in chirps, which are repeated regularly. For $G$. rubens, trills are typical, long sequences of sound pulses with a constant pulse rate (Fig. $1 B$ ). In T. commodus, the calling song consists of two subsections, a chirp followed by one to four long trills. Also in T. oceanicus, the song has two subsections: a trill is followed by a series of chirps. In both species, the pulse rate differs between chirps and trills and the two different subsections are arranged into a larger repeating unit of the song called a phrase (Fig. $1 B$ ) according to the classification of song subsections by Bentley and Hoy (1972). A summary of the song characteristics is presented in Table 1.

During fictive singing, the pulse pattern is revealed in the rhythmic neuronal activity of meso-Nv3A with alternating bursts of wing-opener and wing-closer motoneurons (Fig. 1C).

\section{Comparative morphology of the A3-AO}

The A3-AO neuron has a very similar structure in all of the studied species (Fig. 2). The cell body is located ventrally in the posterior lateral margin of the A3 ganglion (Fig. $2 A$, arrow 1). The primary neurite ascends from the cell body to the neuropil 70$100 \mu \mathrm{m}$ below the dorsal surface and runs toward the midline and crosses to the contralateral side (Fig. $2 A$, arrow 2). At the midline, an extensive dendritic branching pattern spreads from the primary neurite anteriorly $25-40 \mu \mathrm{m}$ beneath the surface (Fig. $2 \mathrm{~A}$, arrow 3 ) and some finer dendrites project posteriorly (Fig. $2 A$, arrow 4). The axon arises from the primary neurite and bends 
Table 1. Song properties and fictive motor pattern in the cricket species studied

\begin{tabular}{|c|c|c|c|c|c|c|c|c|c|c|}
\hline \multirow{2}{*}{$\begin{array}{l}\text { Species ( } N \text { song/ } \\
\text { fictive pattern) }\end{array}$} & \multicolumn{2}{|c|}{ Pulse duration } & \multicolumn{2}{|c|}{ Pulse period } & \multicolumn{2}{|c|}{ Number of pulses } & \multicolumn{2}{|c|}{ Song/phrase duration ${ }^{c}$} & \multicolumn{2}{|c|}{ Song/phrase period ${ }^{C}$} \\
\hline & Song (ms) & Fictive $(\mathrm{ms})^{a}$ & Song (ms) & Fictive (ms) ${ }^{b}$ & Song & Fictive & Song & Fictive & Song & Fictive \\
\hline $\begin{array}{r}\text { G. bimaculatus } \\
\qquad(N=5 / 5)\end{array}$ & $18.6 \pm 3.2$ & $20.9 \pm 2.9$ & $38.2 \pm 3.2$ & $43 \pm 3.6$ & $3.8 \pm 0.5$ pulses $/$ chirp & $4.5 \pm 1$ pulses/chirp & $130 \pm 24 \mathrm{~ms}$ & $188 \pm 5 \mathrm{~ms}$ & $408 \pm 51 \mathrm{~ms}$ & $459 \pm 92 \mathrm{~ms}$ \\
\hline $\begin{array}{l}\text { G. assimilis } \\
\qquad(N=8 / 8)\end{array}$ & $8.1 \pm 1.3$ & $8.5 \pm 2.5$ & $16.7 \pm 1.5$ & $23.8 \pm 5.4$ & $6.3 \pm 1.1$ pulses/chirp & $6.8 \pm 1$ pulses/chirp & $102 \pm 14 \mathrm{~ms}$ & $142 \pm 22 \mathrm{~ms}$ & $1.5 \pm 0.4 \mathrm{~s}$ & $1.1 \pm 0.4 \mathrm{~s}$ \\
\hline $\begin{array}{l}\text { G. rubens } \\
\qquad(N=8 / 8)\end{array}$ & $11.1 \pm 2.2$ & $14.8 \pm 3$ & $26.3 \pm 4$ & $27.3 \pm 6.6$ & $62 \pm 34$ pulses/trill & $44 \pm 19$ pulses/trill & $1.5 \pm 0.7 \mathrm{~s}$ & $1.1 \pm 0.7 \mathrm{~s}$ & $2 \pm 1 s$ & $1.3 \pm 0.7 \mathrm{~s}$ \\
\hline $\begin{array}{l}\text { T. commodus } \\
\qquad(N=8 / 4)\end{array}$ & $\begin{array}{l}\text { Chirp: } 30.4 \pm 2.4 \\
\quad \text { trill } 22.4 \pm 2\end{array}$ & $\begin{array}{l}\text { Chirp: } 21.8 \pm 5.5 \\
\text { trill } 15.4 \pm 3.6\end{array}$ & $\begin{array}{l}\text { Chirp: } 60.9 \pm 4.5 \\
\quad \text { trill } 33.9 \pm 1.9\end{array}$ & $\begin{array}{l}\text { Chirp: } 71.1 \pm 11 \\
\quad \text { trill } 42.2 \pm 7.8\end{array}$ & $\begin{array}{l}\text { Chirp: } 0.5 \pm 0.4 \text { pulses/chirp; } \\
\text { trill } 9 \pm 1.1 \text { pulses/trill }\end{array}$ & $\begin{array}{l}\text { Chirp: } 9.1 \pm 2 \text { pulses/chirp; } \\
\text { trill l10.3 } \pm 6 \text { pulses/trill }\end{array}$ & $\begin{array}{l}\text { Chirp: } 303 \pm 38 \mathrm{~ms} \\
\quad \text { trill } 1.4 \pm 0.5 \mathrm{~s}\end{array}$ & $\begin{array}{l}\text { Chirp: } 600 \pm 22 \mathrm{~ms} \\
\quad \text { trill } 611 \pm 472 \mathrm{~ms}\end{array}$ & $2.2 \pm 1 \mathrm{~s}$ & $4.2 \pm 1.7 \mathrm{~s}$ \\
\hline $\begin{array}{l}\text { T. oceanicus } \\
\qquad(N=8 / 4)\end{array}$ & $\begin{array}{l}\text { Trill: } 29 \pm 4.3 \\
\quad \text { chirp: } 23.6 \pm 4.2\end{array}$ & $\begin{array}{l}\text { Trill: } 23.2 \pm 0.9 ; \\
\text { chirp: } 16.8 \pm 1.2\end{array}$ & $\begin{array}{l}\text { Trill: } 62.5 \pm 7.7 \\
\text { chirp: } 39.6 \pm 5.1\end{array}$ & $\begin{array}{l}\text { Trill: } 70.3 \pm 15 \\
\quad \text { chirp: } 53.3 \pm 9.3\end{array}$ & $\begin{array}{l}\text { Trill: } 5.5 \pm 0.5 \text { pulses/trill; } \\
\text { chirp: } 2 \pm 0.1 \text { pulses/chirp }\end{array}$ & $\begin{array}{l}\text { Trill: } 8.8 \pm 4.3 \text { pulses/trill; } \\
\text { chirp: } 2 \pm 1.1 \text { pulses/chirp }\end{array}$ & $\begin{array}{l}\text { Trill: } 313 \pm 49 \mathrm{~ms} \\
\quad \text { chirp: } 1.5 \pm 0.5 \mathrm{~s}\end{array}$ & $\begin{array}{l}\text { Trill: } 632 \pm 75 \mathrm{~ms} \\
\quad \text { chirp: } 1.5 \pm 0.7 \mathrm{~s}\end{array}$ & $2 \pm 0.5 \mathrm{~s}$ & $2.3 \pm 1.9 \mathrm{~s}$ \\
\hline
\end{tabular}

a Time between the start of the wing-opener to the start of wing-closer motoneuron activity.

${ }^{\text {b}}$ Time between the start of two consecutive wing-closer motoneuron activities.

In species of the genus Teleogryllus, with complex songs, "phrase" corresponds to both sections of the song.

A

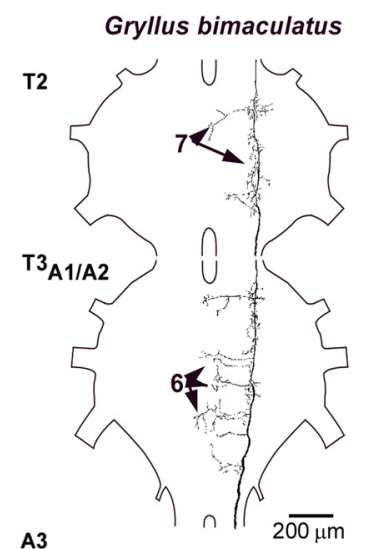

Gryllus assimilis

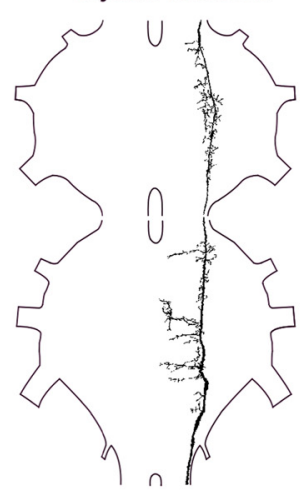

Gryllus rubens

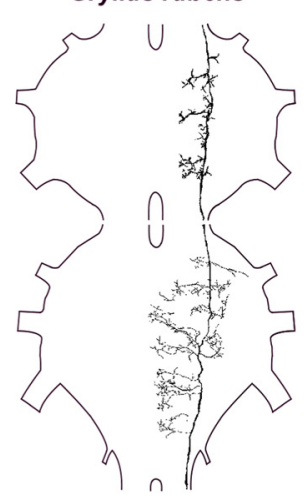

Teleogryllus commodus
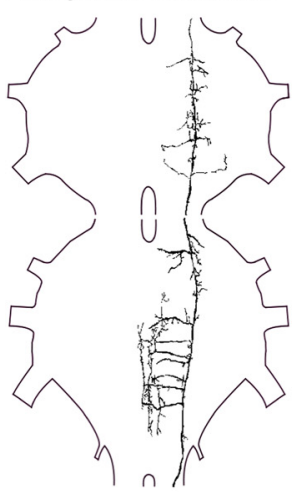

Teleogryllus oceanicus
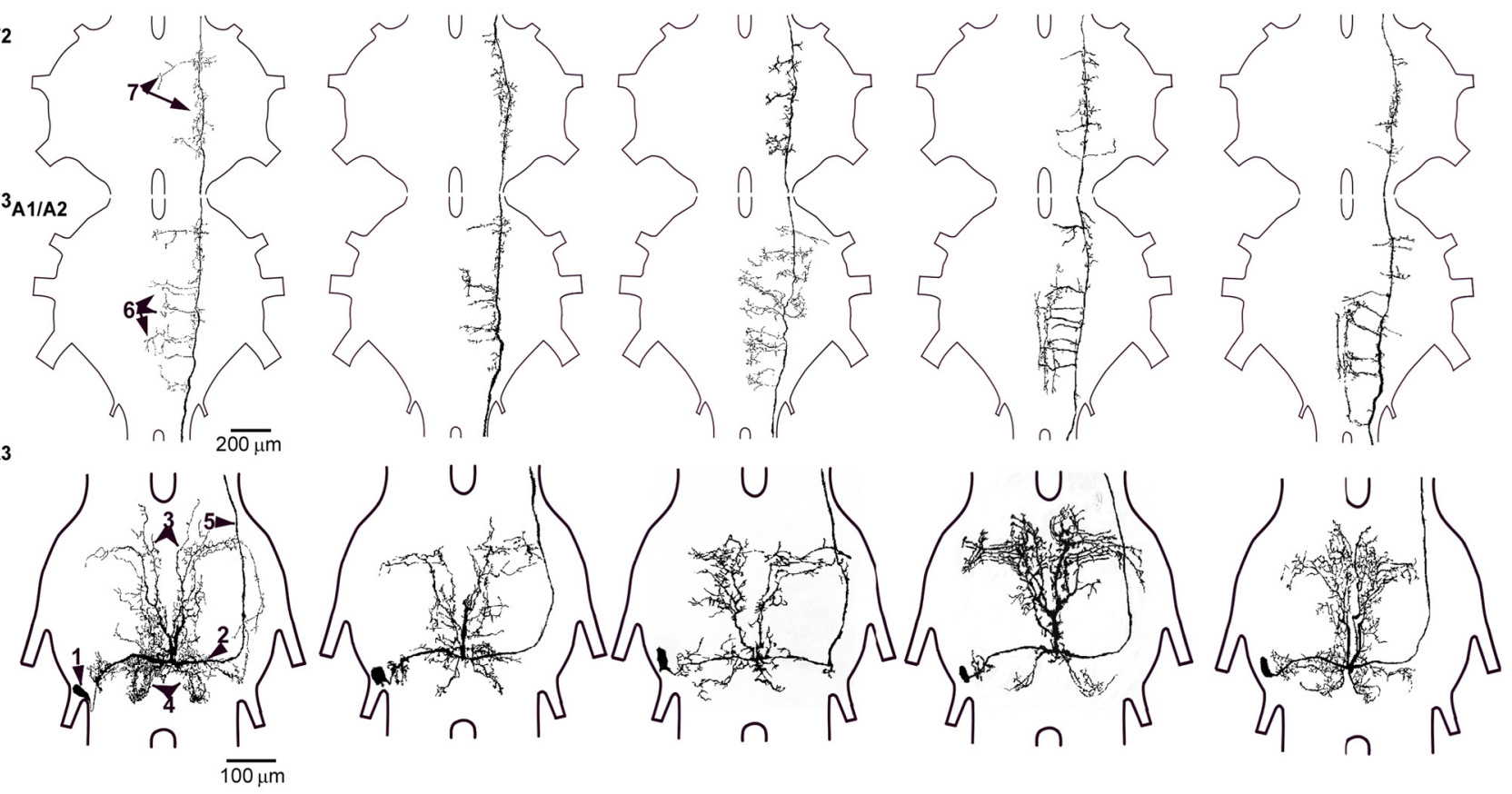

B

\section{T. commodus}

C

Bi

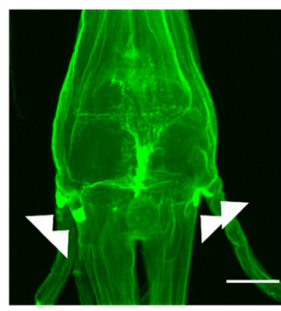

\section{Biii}

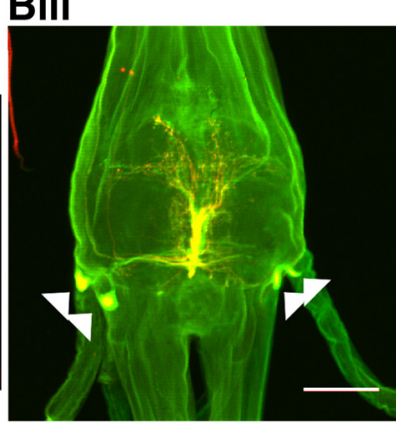

$\mathrm{Ci}$

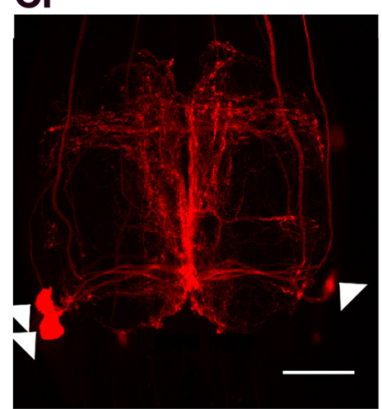

T. oceanicus

Cii

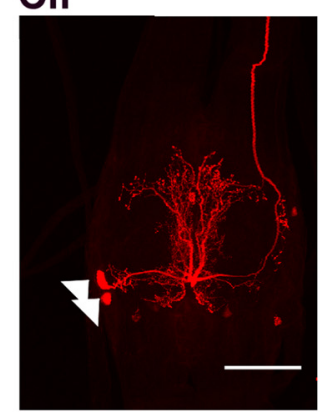

Figure 2. Structure of the abdominal ascending opener interneuron A3-A0 in cricket species. $A$, Morphology of A3-A0 with cell body and dendrites in $\mathrm{A} 3$ and axonal projections in thoracic ganglia $\mathrm{T} 2$ and $\mathrm{T}_{\mathrm{A} 1 / \mathrm{A} 2}$ (dorsal view). B, Maximum-intensity projections of confocal image stacks showing the fluorescence-labeled (Bi, LY, green; Bii, Alexa Fluor 568, red) arborizations of the two pairs of bilateral symmetrical A3-A0 in T. commodus. Both stainings reveal dye coupling between the left and right neurons. The intracellular injection of the two dyes was performed in the same animal in different regions of the A3 ganglion. The merge (Biii) of the two projections shows a perfect correspondence between the two stainings. Arrows mark the cell bodies. Scale bars, $150 \mu \mathrm{m}$. C, In $T$. oceanicus, maximum-intensity projections of confocal image stacks of staining a single interneuron with neurobiotin-avidinCy3 revealed the arborizations of two pairs of bilateral $\mathrm{A} 3$ - $\mathrm{A} 0 \mathrm{interneu-}$ rons. Ci, In one animal, two cell bodies occurred unilaterally on the left side and one cell body on the right side. Cii, Another staining revealed two cell bodies unilaterally on the left side. Arrows mark the cell bodies. Scale bars, $150 \mu \mathrm{m}$. 
laterally toward anterior and projects at the margin of the contralateral connective toward the thoracic ganglia (Fig. $2 \mathrm{~A}$, arrow $5)$. In the metathoracic ganglion complex ( $\left.\mathrm{T} 3_{\mathrm{A} 1 / \mathrm{A} 2}\right)$, four to seven prominent axon collaterals project dorsally toward the midline (Fig. 2A, arrow 6); in the mesothoracic ganglion (T2), a further two to five smaller collaterals project in a similar manner (Fig. $2 A$, arrow 7 ). The axon continues to the prothoracic ganglion (T1); however, details of the structure could not be revealed. In all Gryllus species, the A3-AO occurs as one bilateral pair of neurons showing dye coupling.

In addition to these similarities among the A3-AO neurons in Gryllus, there are also some differences. $\mathrm{A} 3-\mathrm{AO}_{\text {bimac }}(N=5$; Fig. $2 A$ ) has a very symmetrical dendritic branching pattern in the anterior region of the A3 ganglion; however, in the two NorthAmerican species, dendrites are more branched on the contralateral side. In the $\mathrm{T} 3_{\mathrm{A} 1 / \mathrm{A} 2}$, the $\mathrm{A} 3-\mathrm{AO}_{\text {assim }}$ has fewer and finer dendrites that are restricted to the midline of the ganglion $(N=8$; Fig. 2A). In $\mathrm{A} 3-\mathrm{AO}_{\text {rubens }}$, several axon collaterals in the $\mathrm{T} 3_{\mathrm{A} 1 / \mathrm{A} 2}$ project toward the lateral region of the ganglion $(N=8$; Fig. $2 A)$. The extensive dendritic arborization in the $\mathrm{A} 3$ ganglion and axon collaterals in Teleogryllus are very similar to the $\mathrm{A} 3-\mathrm{AO}_{\text {bimac }}$. As a fundamental difference from Gryllus, in Teleogryllus, the number of A3-AO neurons is higher. In T. commodus, a second pair of bilateral interneurons was always stained via dye coupling in recordings with neurobiotin $(N=2)$ or Alexa Fluor 568 and LY $(N=2)$. In three of four T. oceanicus stainings of A3-AO $\mathrm{Acean}_{\text {with }}$ neurobiotin $(N=2)$ or with Alexa Fluor $568(N=1)$, three cell bodies (Fig. 2C, left) were labeled, whereas in one animal, two cell bodies were labeled on the same side (Fig. 2C, right; Alexa Fluor 568).

\section{Activity of A3-AO interneuron during fictive calling song}

The stereotypical pattern of the motor activity allowed an identification of the corresponding song patterns (Fig. 1C) and to quantify the features of the singing activity (Table 1). During fictive singing, the pulse period across the species increased by 4-30\%; however, the characteristics and temporal organization of the fictive calling song corresponded to the natural calling song of each species (Table 1).

In the genus Gryllus, brain stimulation induces reliably calling song motor pattern. However, in the genus Teleogryllus, this was not the case. In $T$. commodus $(N=17)$, only four generated sustained periods of calling song, with 13 male generating mixed motor patterns; that is, the production of long chirps resembling the aggressive song or a mixture of calling and courtship songs (Loher and Rence, 1978; Paripovic et al., 1996). In T. oceanicus, four of 17 generated sustained periods of fictive calling song.

In all species, the $\mathrm{A} 3-\mathrm{AO}$ interneuron was identified by its rhythmic activity in phase with the wing-opener motor pattern (Fig. 3). Before each singing episode (chirps or trills), a gradual increase in membrane potential (ramp depolarization) occurred that culminated with the start of the burst depolarization of the A3-AO (Figs. 3, 4, blue highlight, Table 2). During the intervals between singing episodes, spiking ceased and there was only weak synaptic activity. A single opener-closer cycle is characterized by a rapid depolarization of $\mathrm{A} 3-\mathrm{AO}$ preceding the wing-opener activity (Fig. 3Aii-Eii, open circles), followed by a hyperpolarization preceding the wing-closer activity (Fig. 3Aii-Eii, closed circles). Recordings from the main neurite revealed a burst of spikes of $0.3-1.2 \mathrm{mV}$ amplitude riding on top of a 10-18 $\mathrm{mV}$ amplitude depolarization (Fig. 3Aii-Eii, arrowheads). In all species, the latency between the first spike of an A3-AO burst and the subsequent wing-opener activity was very short and stable (9-12 ms;
Table 3). In addition to these general features, the neurons exhibit species-specific characteristics, which are summarized in Figures 3 and 4 and Tables 2 and 3.

In $G$. bimaculatus, each chirp is initiated by a gradual ramp depolarization starting $42 \pm 6.4 \mathrm{~ms}$ before a chirp and reaching an amplitude of $6 \pm 0.5 \mathrm{mV}$ at the beginning of the pulse pattern (Figs. $3 A$ ii, $4 A i$, blue highlight; Table $2 ; N=5$ animals, $n=50$ chirps). For each pulse period, the membrane potential oscillations of $\mathrm{A} 3-\mathrm{AO}_{\text {bimac }}$ (Figs. $3 \mathrm{~A}, 4 \mathrm{~A}$ ) consisted of a $17.5 \pm 2.1 \mathrm{mV}$ amplitude depolarization generating a burst of $4-6$ spikes followed by a $9.2 \pm 2.5 \mathrm{mV}$ hyperpolarization (Table 3). H-to-T took $17 \pm 6.7 \mathrm{~ms}$ and T-to-S took $4.1 \pm 1.7 \mathrm{~ms}(N=5, n=50$; Table 2); the rise of the membrane potential to the first spike of a burst occurred with $4.3 \mathrm{mV} / \mathrm{ms}$.

In G. assimilis, the ramp depolarization starts $40 \pm 7 \mathrm{~ms}$ before a chirp and reaches an amplitude of $4.3 \pm 1.3 \mathrm{mV}$ (Figs. 3Bii, 4Bi, Table 2; $N=10, n=100$ ). During a chirp, the membrane potential is maintained at $2-4 \mathrm{mV}$ above the resting potential, whereas the activity of $\mathrm{A} 3-\mathrm{AO}_{\text {assim }}$ (Fig. $3 \mathrm{~B}$ ) varies during the chirp pattern. A sequence of five to eight pronounced depolarization-repolarization cycles is superimposed on the elevated membrane potential. The depolarization amplitude of the first and last pulse is the smallest, $11 \pm 2 \mathrm{mV}$ and $10.4 \pm 3.1 \mathrm{mV}$, respectively (Table $3 ; N=10$ animals, $n=100$ chirps), whereas the middle pulses have a mean amplitude of $14.9 \pm 4.6 \mathrm{mV}$ (Fig. $3 B$, Table $3: N=10, n=100$ ). The last burst is terminated by a pronounced transient hyperpolarization of $11.7 \pm 3.1 \mathrm{mV}$ preceding the final closer activity $(N=10, n=100$; Table 3). Because the second burst has the most pronounced depolarization, its transition phase was analyzed in detail. For this burst, the H-to-T took $9.1 \pm 0.6 \mathrm{~ms}$, the T-to-S was $1.9 \pm 0.5 \mathrm{~ms}(\mathrm{~N}=10$, $n=100$; Table 2), and the rise of the membrane potential to the first spike of this burst occurred within $7.6 \mathrm{mV} / \mathrm{ms}$.

In $G$. rubens, the ramp depolarization begins $21 \pm 2.1 \mathrm{~ms}$ before a trill and reaches $2.9 \pm 0.4 \mathrm{mV}$ (Fig. 4Ci, Table 2; $N=10$, $n=70)$. During a trill, the $\mathrm{A} 3-\mathrm{AO}_{\text {rubens }}$ membrane potential rhythmically oscillates in phase with the pulse pattern (Fig. $3 C$ ). Preceding each subsequent opener activity, the neuron generates a $10.5 \pm 4.7 \mathrm{mV}$ amplitude depolarization with $2-4$ spikes (Table 3; $N=10, n=70$ trills). Each depolarization is followed by a hyperpolarization of $8.1 \pm 3.5 \mathrm{mV}$ (Table $3 ; N=10, n=70$ ) preceding the following closer activity. H-to-T takes $12 \pm 3.3 \mathrm{~ms}$ and T-to-S takes $4.7 \pm 2.3 \mathrm{~ms}(N=10, n=70$; Table 2$)$; at the start of a burst, the membrane potential changes at a rate of $2.3 \mathrm{mV} / \mathrm{ms}$.

In T. commodus (Fig. 3D), the rhythmic activity of A3$\mathrm{AO}_{\text {comm }}$ mirrors the chirp and trill sections. The ramp depolarization starts $101 \pm 11 \mathrm{~ms}$ before a chirp and reaches an amplitude of $4.1 \pm 2.2 \mathrm{mV}$ (Fig. $4 D i$, Table $2 ; N=4, n=40$ ). During chirps, each depolarization of $16.4 \pm 4.1 \mathrm{mV}$ (Table 3; $N=4, n=40$ song phrases) generates $3-7$ spikes followed by a hyperpolarization of $10.1 \pm 3.2 \mathrm{mV}$ (Table $3: N=4, n=40$ ). During trills, the amplitude of the depolarization is $13.4 \pm 3.8$ $\mathrm{mV}$ (Table $3 ; N=4, n=40$ ) with 3-9 spikes, followed by a $6.5 \pm$ $2.5 \mathrm{mV}$ hyperpolarization (Table $3 ; N=4, n=40$ ). The H-to-T is $35 \pm 4 \mathrm{~ms}$ during a chirp and $14 \pm 2.1 \mathrm{~ms}$ during a trill, the T-to-S is $7.5 \pm 0.5 \mathrm{~ms}$ during a chirp and $4.5 \pm 1.2 \mathrm{~ms}$ during a trill $(N=4, n=40$; Table 2$)$. The membrane potential at the beginning of a burst increases with $2.2 \mathrm{mV} / \mathrm{ms}$ during a chirp and with $3 \mathrm{mV} / \mathrm{ms}$ during a trill $(N=4, n=40)$.

In T. oceanicus (Fig. $3 E$ ) the rhythmic activity of $\mathrm{A} 3-\mathrm{AO}_{\text {ocean }}$ clearly reveals the trill and the chirp sections of the song (Fig. $3 E$ ). The ramp depolarization begins $51 \pm 15 \mathrm{~ms}$ before a trill reaching an amplitude of $2.8 \pm 0.1 \mathrm{mV}$ (Fig. 4Ei, Table $2 ; N=4, n=40$ ). 
Ai Gryllus bimaculatus

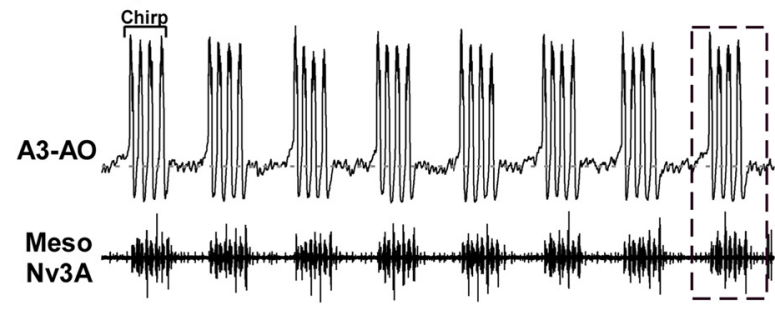

Bi

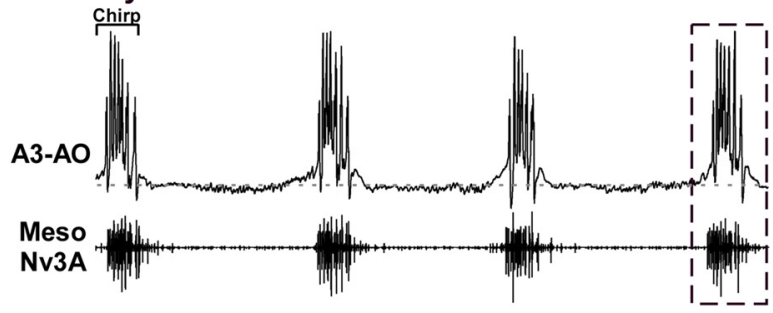

Ci

Gryllus rubens

A3-AO

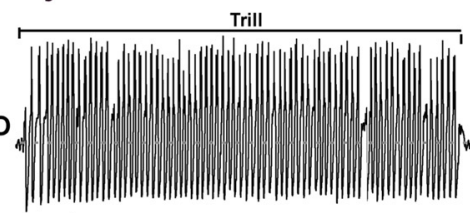

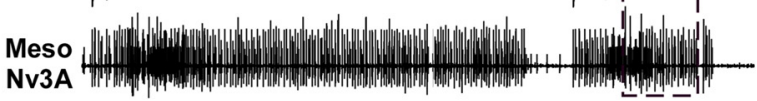

Di Teleogryllus commodus

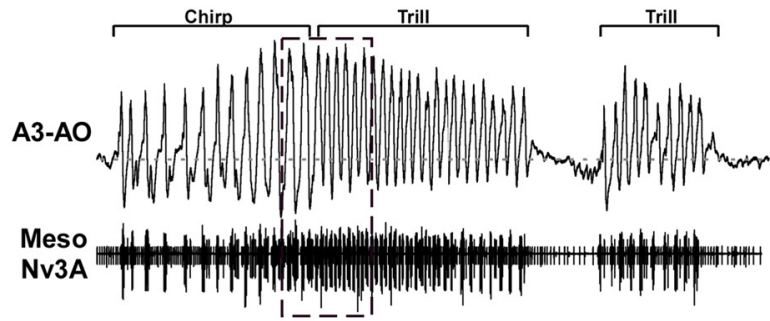

\section{Ei Teleogryllus oceanicus}
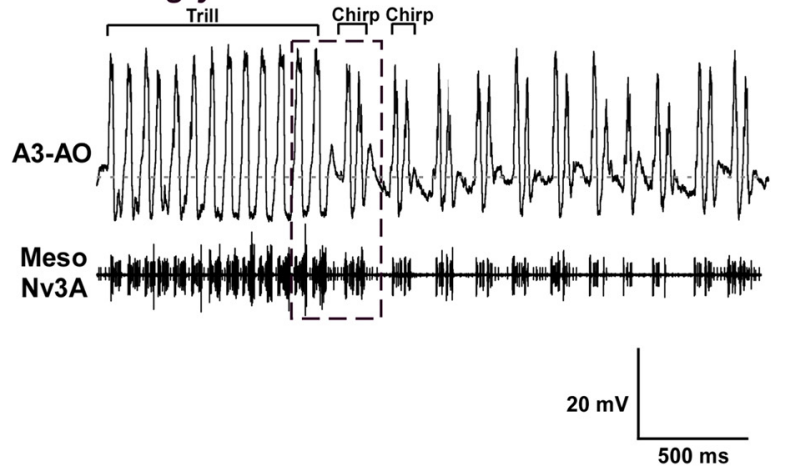

Aii

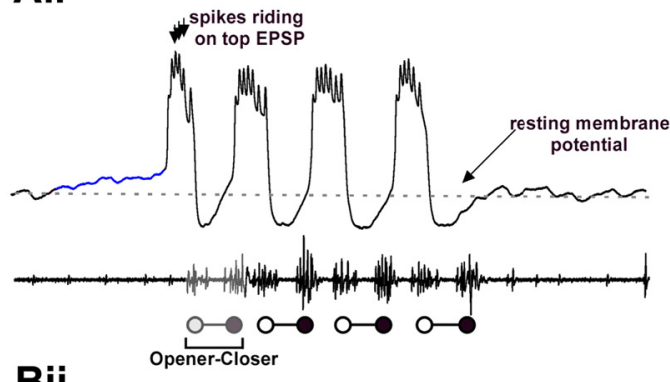

Bii

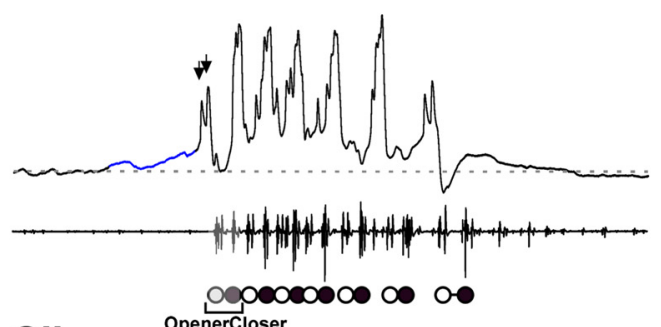

Cii
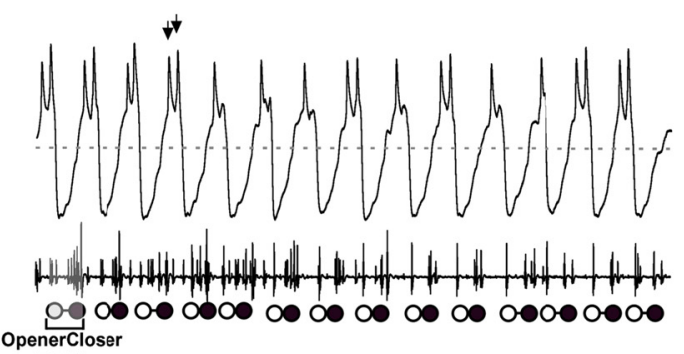

Dii

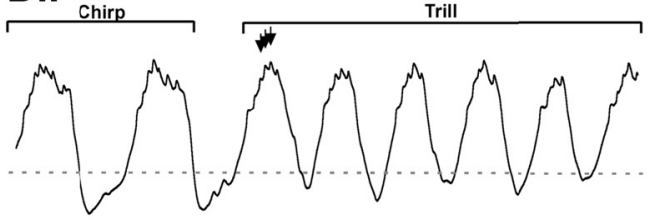

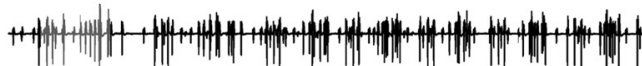
Opener-Closer

Eii

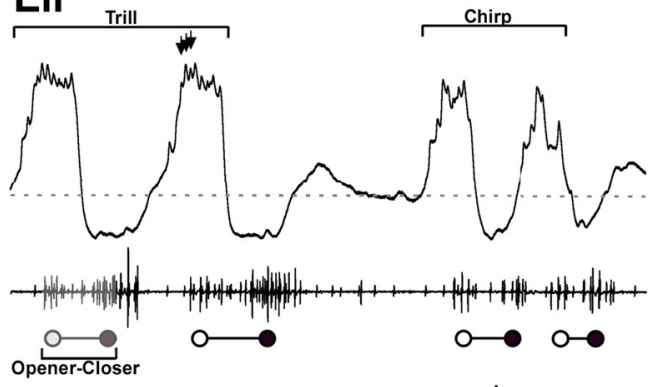

Figure 3. Intracellularly recorded activity of A3-A0 in the different cricket species. A-E, Activity of the A3-A0 (top trace) and singing motor pattern (meso-Nv3A, bottom trace). Ai-Ei, Black dashed box shows the section highlighted at higher temporal resolution in Aii-Eii; the gray horizontal dashed line represents the resting membrane potential. Aii-Eii, During fictive singing A3-A0 depolarized and spiked in phase with wing-opener activity (open circles) and was hyperpolarized in phase with the wing-closer activity (closed circles). Arrows indicate small spikes riding on a large EPSP. The ramp depolarization is marked in blue in Aii and Bii. 
Ai

Aii

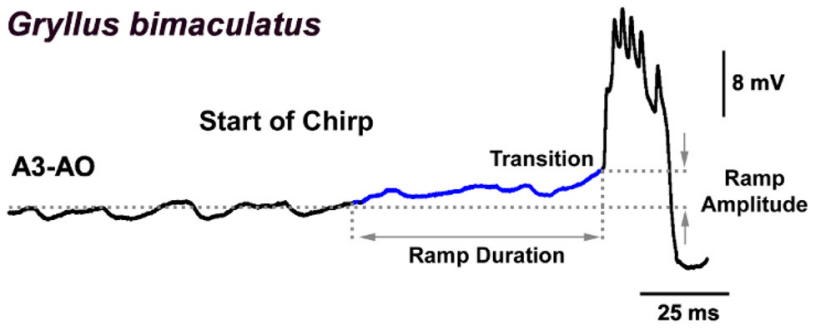

Bi

$\mathrm{Bii}$
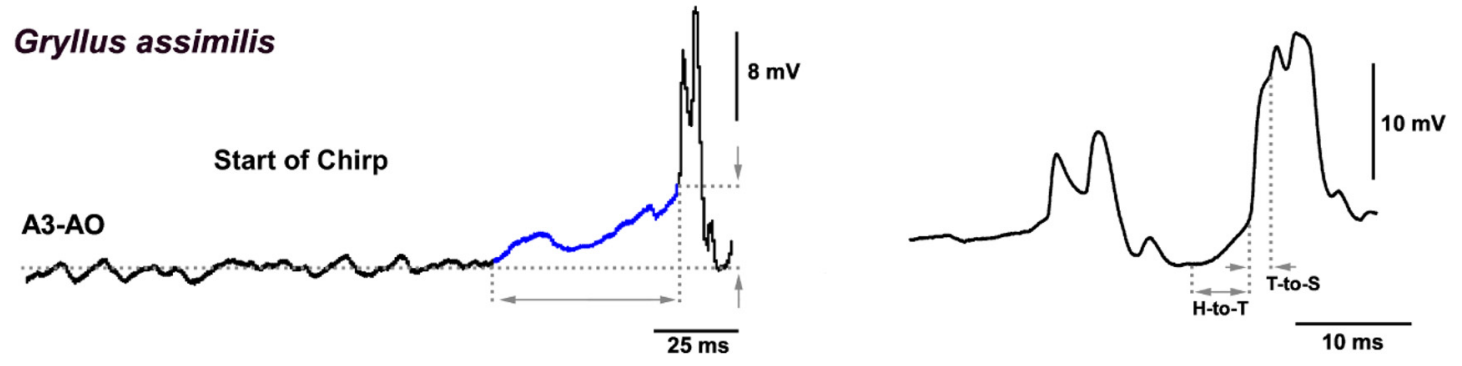

Ci

Cii

\section{Gryllus rubens}
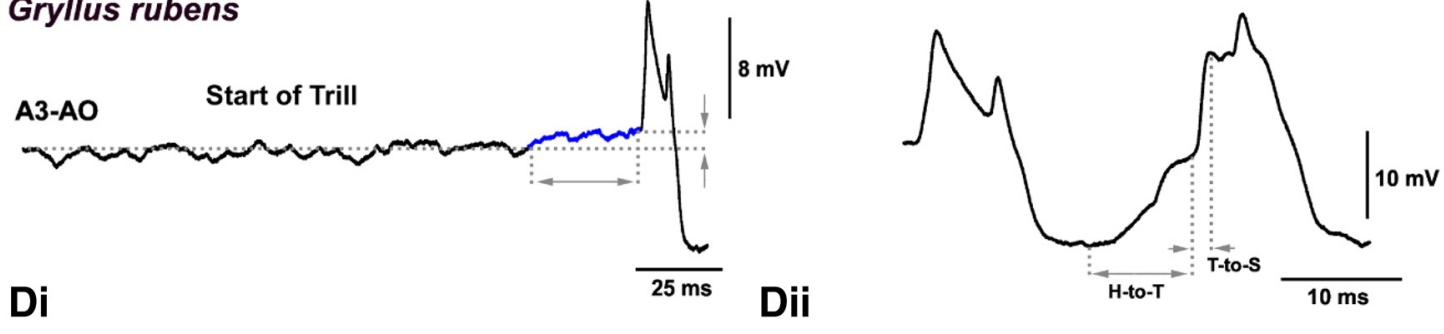

Teleogryllus commodus
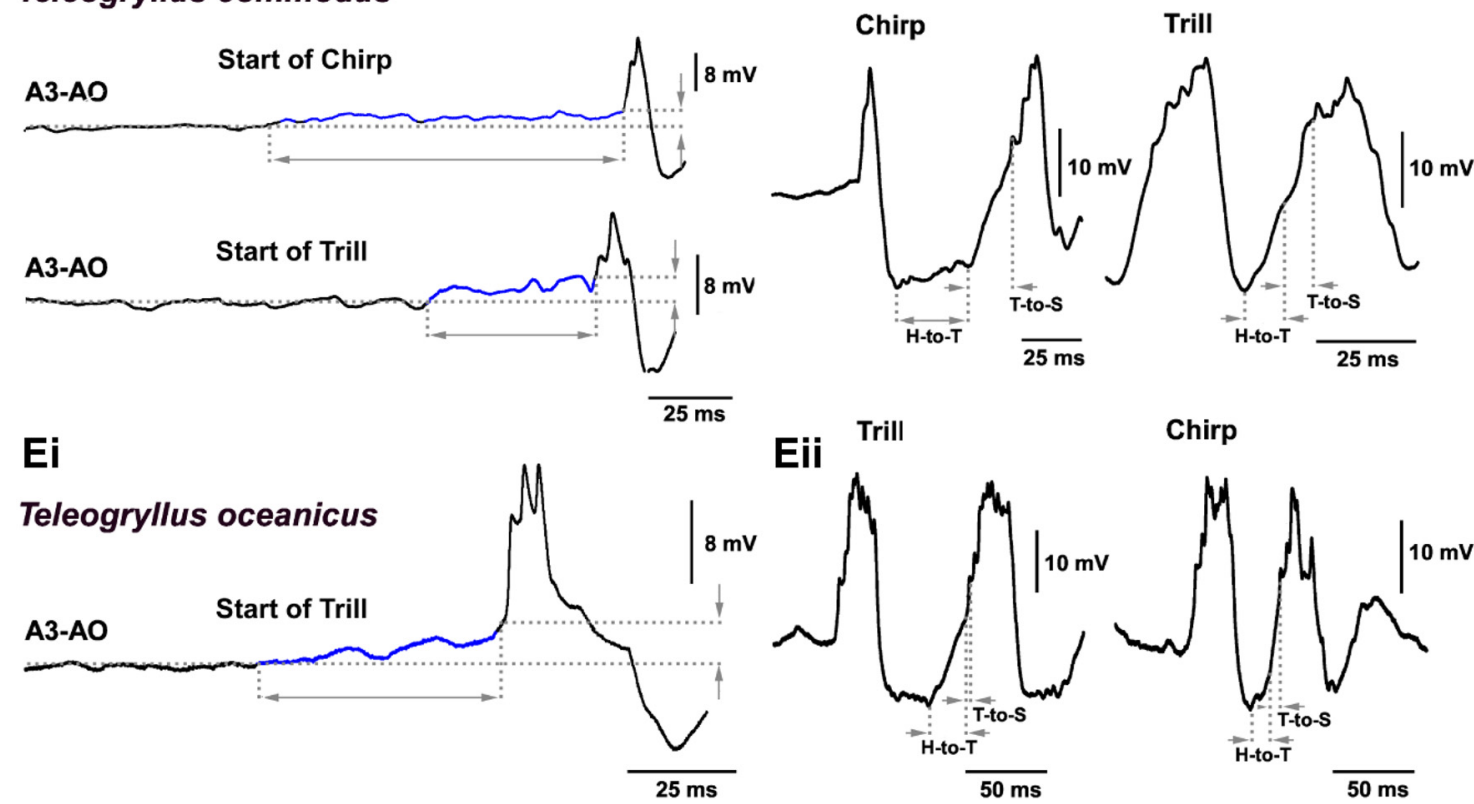

Chirp

Figure 4. Ramp depolarization and membrane potential changes in $A 3-A 0 . A-E$, Intracellular recordings of the A3-A0 showing a gradual increase in the membrane potential above the resting potential (horizontal dashed line). This ramp depolarization (blue section) occurred at the start of singing activity before the generation of the first burst depolarization. A horizontal arrow marks the duration of the ramp and vertical stippled lines mark the points used to calculate the amplitude of the ramp; that is, the resting membrane potential and the start of the burst depolarization. Ai-Ei, First two burst depolarizations of a singing episode with details of the membrane potential changes. The peak hyperpolarization is followed by a transition phase (H-to-T, horizontal dashed line), followed by a fast rise in membrane potential that triggers the first spike of the burst (T-to-S, vertical dashed line), as indicated by arrows. 
Table 2. Properties of the A3-A0: ramp depolarization and membrane potential changes

\begin{tabular}{|c|c|c|c|c|c|}
\hline Species ( $N$ animals) & $\begin{array}{l}\text { Start ramp } \\
\text { depolarization (ms) }\end{array}$ & $\begin{array}{l}\text { Amplitude ramp } \\
\text { depolarization (mV) }\end{array}$ & $\begin{array}{l}\text { H-to-T } \\
\text { interval (ms) }\end{array}$ & $\begin{array}{l}\text { T-to-S } \\
\text { interval (ms) }\end{array}$ & $\begin{array}{l}\text { Rate of membrane } \\
\text { potential change (mV/ms) }\end{array}$ \\
\hline $\begin{array}{l}\text { G. bimaculatus } \\
\qquad(N=5 ; n=50 \text { chirps })\end{array}$ & $42 \pm 6.4$ & $6 \pm 0.5$ & $17 \pm 6.7$ & $4.1 \pm 1.7$ & 4.3 \\
\hline $\begin{array}{l}\text { G. assimilis } \\
\qquad(N=10 ; n=100 \text { chirps })\end{array}$ & $40 \pm 7$ & $4.3 \pm 1.3$ & $9.1 \pm 0.6$ & $1.9 \pm 0.5$ & 7.6 \\
\hline $\begin{array}{l}\text { G. rubens } \\
\qquad(N=10 ; n=70 \text { trills })\end{array}$ & $21 \pm 2.1$ & $2.9 \pm 0.4$ & $12 \pm 3.3$ & $4.7 \pm 2.3$ & 2.3 \\
\hline $\begin{array}{l}\text { T. commodus } \\
\qquad(N=4 ; n=40 \text { chirps/trills })\end{array}$ & $\begin{array}{r}\text { Chirp: } 101 \pm 11 ; \\
\text { trill: } 47 \pm 5.5\end{array}$ & $\begin{array}{l}\text { Chirp: } 4.1 \pm 2.2 \\
\text { trill: } 4.7 \pm 1.4\end{array}$ & $\begin{array}{l}\text { Chirp: } 35 \pm 4 \\
\quad \text { trill: } 14 \pm 2.1\end{array}$ & $\begin{array}{l}\text { Chirp: } 7.5 \pm 0.5 \\
\quad \text { trill: } 4.5 \pm 1.2\end{array}$ & Chirp: 2.2; trill: 3 \\
\hline $\begin{array}{l}\text { T. oceanicus } \\
\qquad(N=4 ; n=40 \text { chirps/trills })\end{array}$ & $\begin{array}{l}\text { Trill: } 51 \pm 15 \text {; chirp: } \\
\text { not analyzed, chirp } \\
\text { intervals }<100 \mathrm{~ms}\end{array}$ & $\begin{array}{r}\text { Trill: } 2.8 \pm 0.1 \text {; chirp: } \\
\text { not analyzed, chirp } \\
\text { intervals }<100 \mathrm{~ms}\end{array}$ & $\begin{array}{l}\text { Trill: } 35 \pm 4 \\
\quad \text { chirp: } 18 \pm 0.1\end{array}$ & $\begin{array}{l}\text { Trill: } 4.2 \pm 0.4 \\
\quad \text { chirp: } 3.8 \pm 0.2\end{array}$ & Chirp: 3.7 ; trill: 3.6 \\
\hline
\end{tabular}

Table 3. Properties of the A3-A0: spike and burst activity

\begin{tabular}{|c|c|c|c|c|}
\hline Species ( $N$ animals) & $\begin{array}{l}\text { Spikes per } \\
\text { pulse }\end{array}$ & $\begin{array}{l}\text { Spike delay to wing-opener } \\
\text { motoneurons (ms) } \bar{x} \pm S D\end{array}$ & $\begin{array}{l}\text { Depolarization } \\
\text { amplitude (mV) }\end{array}$ & $\begin{array}{l}\text { Hyperpolarization } \\
\text { amplitude (mV) }\end{array}$ \\
\hline G. bimaculatus $((N=5 ; n=50$ chirps $)$ & $4-6$ & $10.4 \pm 1.2$ & $17.5 \pm 2.1$ & $9.2 \pm 2.5$ \\
\hline G. assimilis $((N=10 ; n=100$ chirps $)$ & $3-6$ & $8.9 \pm 1.2$ & $\begin{array}{c}1^{\text {st. }}: 11 \pm 2.0 \\
\text { Middle: } 14.9 \pm 4.6 \\
\text { Last: } 10.4 \pm 3.1\end{array}$ & $\begin{array}{c}1^{\text {st. }}: 9.8 \pm 2.7 \\
\text { Middle: } 7.5 \pm 1.4 \\
\text { Last: } 11.7 \pm 3.1\end{array}$ \\
\hline G. rubens ( $N=10 ; n=70$ trills) & $2-4$ & $9.8 \pm 1.4$ & $10.5 \pm 4.7$ & $8.1 \pm 3.5$ \\
\hline T. commodus ( $N=4 ; n=40$ chirps/trills) & $\begin{array}{l}\text { Chirp: 3-7 } \\
\text { Trill: 3-9 }\end{array}$ & $\begin{array}{l}\text { Chirp: } 11.6 \pm 1.4 \\
\text { Trill: } 11.2 \pm 1.3\end{array}$ & $\begin{array}{l}\text { Chirp: } 16.4 \pm 4.1 \\
\text { Trill: } 13.4 \pm 3.8\end{array}$ & $\begin{array}{c}\text { Chirp: } 10.1 \pm 3.2 \\
\text { Trill: } 6.5 \pm 2.5\end{array}$ \\
\hline T. oceanicus ( $N=4 ; n=40$ chirps/trills) & $\begin{array}{l}\text { Trill: } 4-6 \\
\text { Chirp: } 2-5\end{array}$ & $\begin{array}{l}\text { Trill: } 10.9 \pm 2.3 \\
\text { Chirp: } 11.0 \pm 2.3\end{array}$ & $\begin{array}{l}\text { Trill: } 15.9 \pm 5.2 \\
\text { Chirp: } 13.6 \pm 4.2\end{array}$ & $\begin{array}{c}\text { Trill: } 9.5 \pm 3.9 \\
\text { Chirp: } 7.2 \pm 3.3\end{array}$ \\
\hline
\end{tabular}

During the trill, the rhythmic depolarization preceding the opener activity is $15.9 \pm 5.2 \mathrm{mV}$ in amplitude (Table $3 ; N=4$, $n=40$ song phrases), generating $4-6$ spikes, and each depolarization is followed by a hyperpolarization of $9.2 \pm 3.9 \mathrm{mV}$ (Table 3; $N=4, n=40)$. During the chirps, the depolarization has an amplitude of $13.6 \pm 4.2 \mathrm{mV}$ (Table $3 ; N=4, n=40$ ), generating 2-5 spikes, followed by a hyperpolarization of $7.2 \pm 3.3 \mathrm{mV}$ (Table $3 ; N=4, n=40$ ). H-to-T is $35 \pm 4 \mathrm{~ms}$ during the trill section and $18 \pm 0.1 \mathrm{~ms}$ during the chirp section. T-to-S is $4.2 \pm$ $0.4 \mathrm{~ms}$ during the trill section and $3.8 \pm 0.2 \mathrm{~ms}$ during the chirp section $(N=4, n=40$; Table 2$)$. At the beginning of a burst, the membrane potential increases with $3.7 \mathrm{mV} / \mathrm{ms}$ in the trills and with $3.6 \mathrm{mV} / \mathrm{ms}$ during the chirps.

\section{Initiation and modulation of singing motor patterns by intracellular A3-AO stimulation}

In all species, injection of depolarizing current (4 nA, $155 \mathrm{~ms}$ ) into the main neurite of the A3-AO interneuron elicited oscillations of the membrane potential (Fig. 5A-E) accompanied by alternating opener-closer motoneuron activity in the mesoNv3A. Motor activity ceased with the end of the current injection.

We analyzed the pulse periods and compared the motor activity of the fictive song pattern (blue) with the activity induced by A3-AO current injection (orange), taking the wing-closer activity as a reference (Fig. 5Aiii, inset). In Gryllus species, the pulse periods of fictive singing as elicited by pharmacological brain stimulation (see Materials and Methods) were not significantly different from the pulse periods elicited by A3-AO stimulation. In G. bimaculatus, the median pulse period during fictive singing was $42 \mathrm{~ms}$ (IQR: $39.2 \mathrm{~ms} / 44.8 \mathrm{~ms}, N=4)$ and for A3-AO stimulation it was $39.9 \mathrm{~ms}$ (IQR: $36.4 \mathrm{~ms} / 45.5 \mathrm{~ms}$; Kolmogorov-Smirnov test for equality of distribution functions: $p=0.485, N=4$, $n=5$ stimuli/animal, Fig. 5 Aiii). In G. assimilis, the median pulse period during fictive singing was $20.3 \mathrm{~ms}$ (IQR: $16.1 \mathrm{~ms} / 23.8 \mathrm{~ms}$;
$N=4$ ) and during A3-AO stimulation it was $20.3 \mathrm{~ms}$ (IQR: 16.8 ms/23.8 ms; Kolmogorov-Smirnov test: $p=0.541, N=4, n=5$ stimuli/animal, Fig. 5Biii). For G. rubens, the median pulse period of fictive singing was $26 \mathrm{~ms}$ (IQR: $25 \mathrm{~ms} / 27 \mathrm{~ms} ; N=4$ ) and for A3-AO current injection 24 ms (IQR: 21 ms/26 ms; Kolmogorov-Smirnov test: $p=0.159, N=4, n=10$ stimuli/animal, Fig. 5Ciii).

In Teleogryllus species, the fictive calling song elicited by brain stimulation had a bimodal distribution of pulse periods due to the generation of chirps and trills (Fig. 5Di-Ei). In both species, the first peak of the distribution corresponds to the song phrase with the highest pulse rate (T. commodus: median $41.8 \mathrm{~ms}$ [IQR: $37.4 \mathrm{~ms} / 46.2$ ]; T. oceanicus: median $47.3 \mathrm{~ms}$ [IQR: $40.7 \mathrm{~ms} / 50.6$ $\mathrm{ms}]$; Fig. 5Diii-Eiii, orange; $N=4$ ). The second peak of the distribution corresponds to the song phrase with the lowest pulse rate (T. commodus: median $72.6 \mathrm{~ms}$ [IQR: $66 \mathrm{~ms} / 79.2 \mathrm{~ms}$ ]; $T$. oceanicus median $70.4 \mathrm{~ms}$ [IQR: $66 \mathrm{~ms} / 77 \mathrm{~ms}$ ]; Fig. 5Diii-Eiii, blue; $N=4$ ). Intracellular A3-AO stimulation induced shorter pulse periods than either of these: the median pulse period was $28.6 \mathrm{~ms}$ (IQR: $25.3 \mathrm{~ms} / 30.8 \mathrm{~ms}$ ) in T. commodus and $34.1 \mathrm{~ms}$ (IQR: $28.6 \mathrm{~ms} / 42.9 \mathrm{~ms}$ ) in T. oceanicus. The pulse periods correspond most closely to the faster sections of the fictive song, but they were significantly shorter (Kolmogorov-Smirnov test: $T$. commodus $p=0.002, N=4, n=10$ stimuli/animal, Fig. 5Diii; $T$. oceanicus $p=0.032, N=4, n=10$ current stimulations per animal, Fig. 5Eiii).

In the fictive motor pattern, slower song sections in terms of pulse period always precede the faster sections. We subsequently tested the response of $\mathrm{A} 3-\mathrm{AO}$ to $3.4 \mathrm{~s}$ current pulses of $+3 \mathrm{nA}$ to determine whether both the slow and fast sections of the songs could be elicited. In both Teleogryllus species, sustained injection of depolarizing current in A3-AO induced different pulse periods.

In T. commodus (Fig. 6Ai), three different types of membrane potential oscillations occurred during long A3-AO depolariza- 
Ai

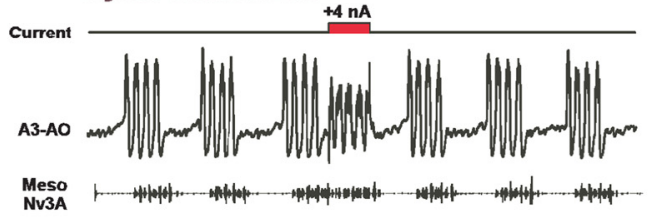

Bi

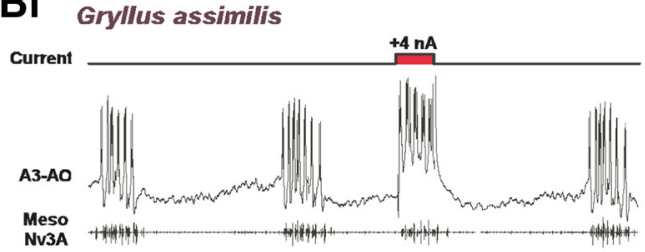

Ci Gryllus rubens

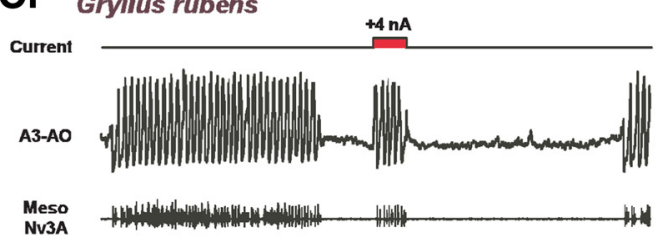

Di Teleogryllus commodus

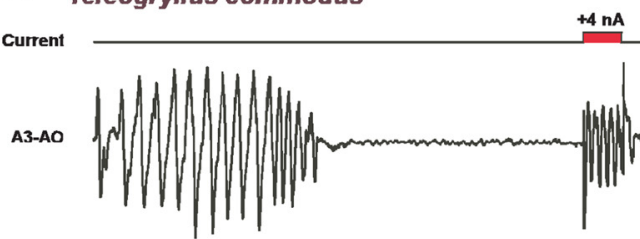

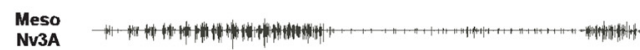

\section{Ei}

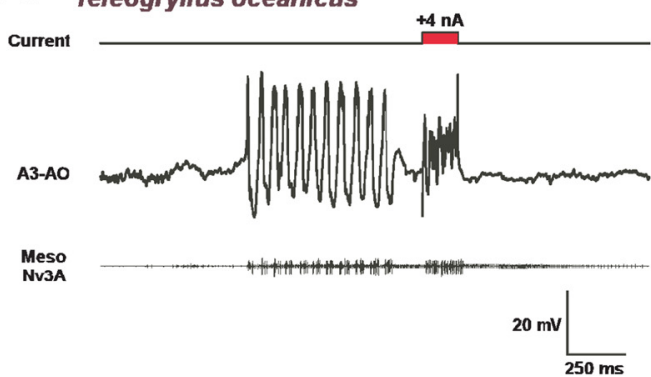

Aii

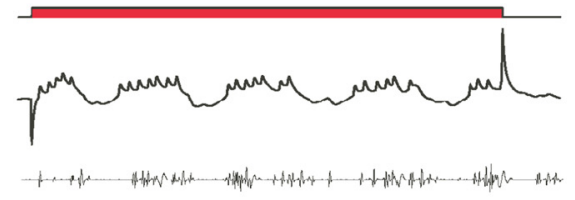

Bii

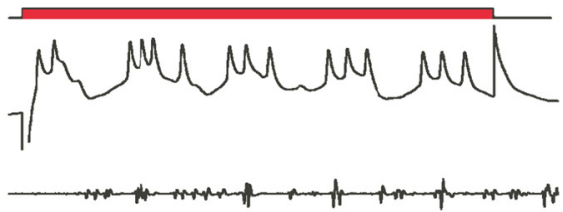

Cii

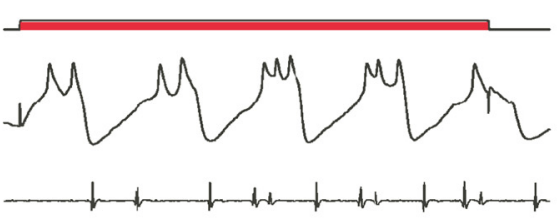

Dii

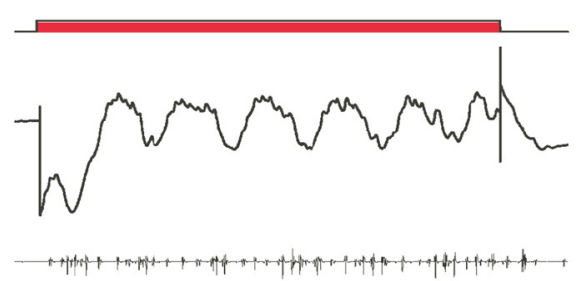

Eii

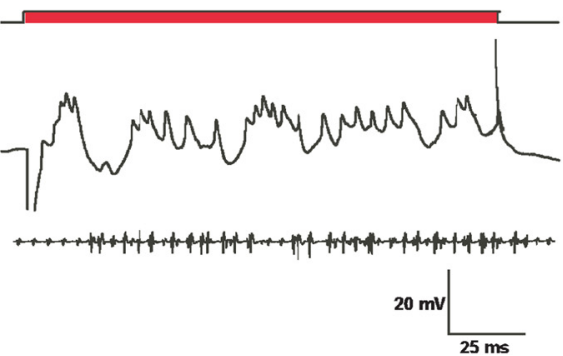

Aiii

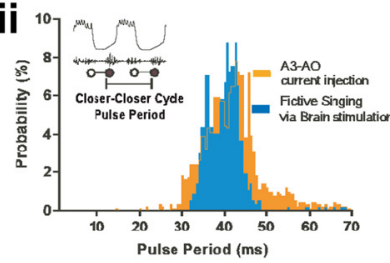

Biii

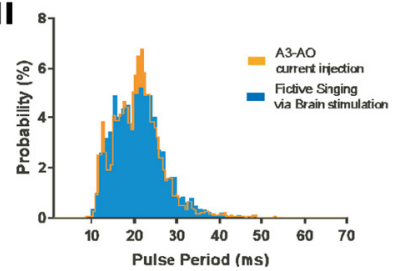

Ciii

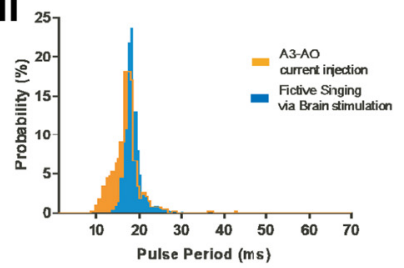

Diii

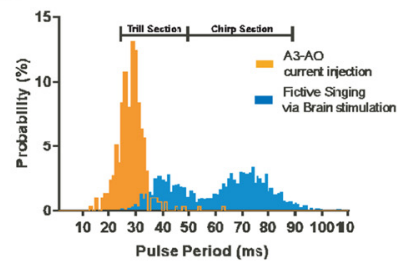

Eiii

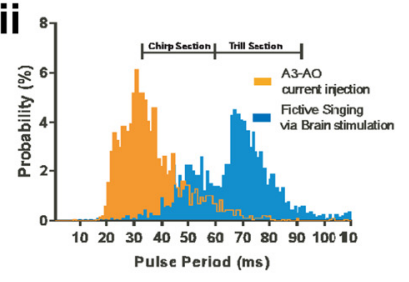

Figure 5. Injection of depolarizing current pulses in A3-A0 elicits singing activity. Ai-Ei, In all species, intracellular injection of $+4 \mathrm{nA}$ for $155 \mathrm{~ms}$ (red bar, top trace) elicited rhythmic A3-A0 activity (middle trace) with depolarization-hyperpolarization cycles and the corresponding singing motor pattern (bottom trace). Aii-Eii, Response driven by the current pulse at a high temporal resolution. Aiii-Eiii, Probability distribution of pulse periods as calculated from the start of wing-closer bursts (see inset in Aii). Pulse periods induced by pharmacological brain stimulation are represented in blue and the ones induced by $\mathrm{A} 3-\mathrm{A} 0$ current injection in orange. Bins are $10 \mathrm{~ms}$. Each distribution was sampled from four animals. For the brain stimulation and current injection, the number of pulse periods analyzed were as follows: in G. bimaculatus, 1138 and 1840; in G. assimilis, 1459 and 1834; in G. rubens, 1247 and 1508; in T. commodus, 1816 and 1198; and in T. oceanicus, 1788 and 1891. The outline of the background histogram (orange) is superimposed over the foreground histogram (blue) to make both histograms clear.

tion. The motor pattern started with a fast section composed of three to six pulses (Fig. 6Aii; see figure legend for details on median pulse period), followed by a slow section with five to 10 pulses (Fig. 6Aii) and a subsequent continuous fast section (Fig. 6Aii). The fast sections had a pulse period similar to a trill section and the slow sections had pulse periods similar to a chirp section.

Three different types of membrane potential oscillations representing the pulse pattern also occurred in T. oceanicus (Fig. 6Bi) following intracellular A3-AO stimulation. Compared with fictive singing, activity started with an unusually fast rhythm (Fig. $6 \mathrm{Bii}$, see figure legend for details on median pulse period), followed by a slower section (Fig. 6Bii), and finally by a section with an intermediate rhythm (Fig. 6Bii). The intermediate section had a pulse period similar to a chirp section and the slow sections had pulse periods similar to a trill section. The fast section elicited by the current injection is surprising in the context of the calling song of T. oceanicus. In addition to this, the organization of the resulting song pattern was different from the fictive calling song because the silent intervals between the trills and chirps were lacking (Fig. 6).

Current injection in A3-AO imposes artificial song patterns Spike activity of A3-AO is sufficient to determine the temporal structure of song episodes in all five species, as demonstrated by intracellular injection of $+4 \mathrm{nA}$ current of different duration and 
Ai Teleogryllus commodus

+3 nA

Current

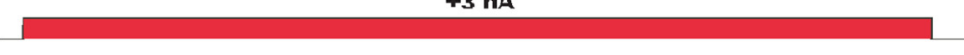

A3-AO

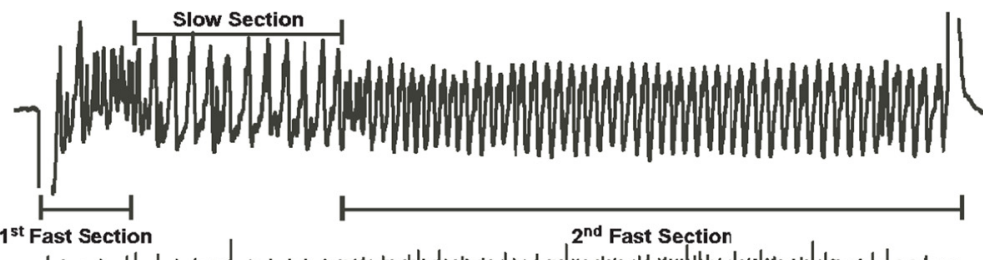

Nv3A

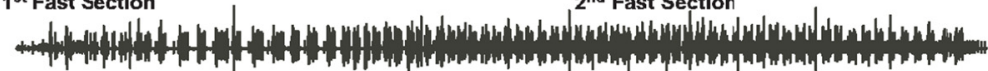

Bi

Teleogryllus oceanicus

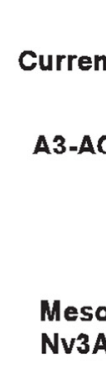

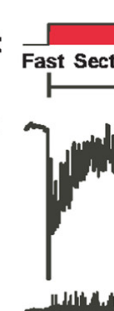

\section{(}

$+3 \mathrm{nA}$
Intermediate Section

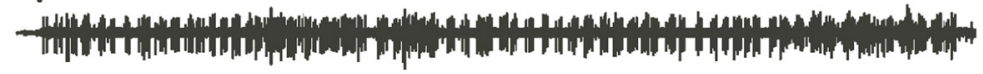

Aii

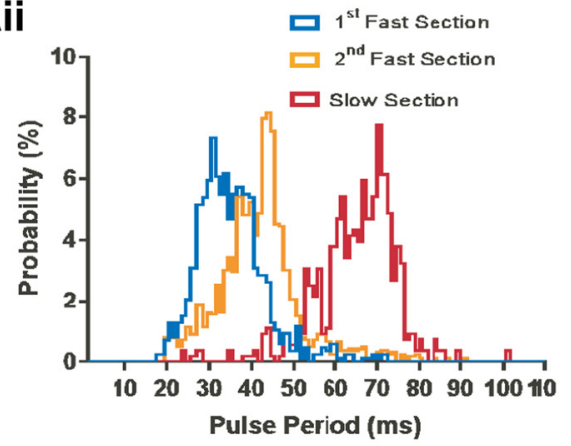

Bii

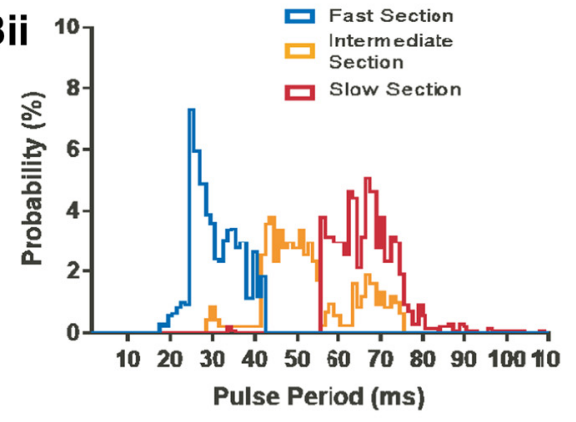

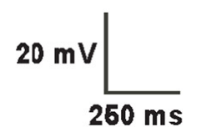

Figure 6. Stimulating A3-AO with long current pulses generates different phases of the song pattern in Teleogryllus species. Ai-Bi, Sustained intracellular injection of $+3 \mathrm{nA}$ for $3.4 \mathrm{~s}$ (red bar, top trace) elicited rhythmic A3-A0 activity (middle trace) and rhythmic singing motor pattern (bottom trace) until the current injection ceased. In T. commodus, three different types of membrane potential oscillations occurred during long A3-A0 depolarization. The motor pattern started with a fast section composed of three to six pulses (first fast section; median pulse period: $34.9 \mathrm{~ms}$, IQR: $31.7 \mathrm{~ms} / 37.6 \mathrm{~ms}$ ), followed by a slow section with 5-10 pulses (median pulse period:60.5 ms, IQR: $56.6 \mathrm{~ms} / 64.3 \mathrm{~ms}$ ) and a subsequent continuous fast section (second fast section; median pulse period: $41.3 \mathrm{~ms}$, IQR: $38.3 \mathrm{~ms} / 44.4 \mathrm{~ms}$ ). In T. oceanicus, activity started with an unusually fast rhythm (fast section; median pulse period: $27.7 \mathrm{~ms}$, IQR: $25.1 \mathrm{~ms} / 30.5 \mathrm{~ms}$ ), followed by a slow section (median pulse period: $63.4 \mathrm{~ms}$, IQR: $57.4 \mathrm{~ms} / 69.1 \mathrm{~ms}$ ), and finally by section with an intermediate rhythm (intermediate section; median pulse period: $42.5 \mathrm{~ms}$, IQR: $39.4 \mathrm{~ms} / 46.3 \mathrm{~ms}$ ). Aii-Bii, Frequency distribution of pulse periods as calculated from the start of wing-closer bursts. The different phases of the singing episode are identified based on the pulse periods. The duration of the pulse period is $(x$-axis) is plotted against the number of occurrences of each pulse period; the bin width is $10 \mathrm{~ms}$. In both species, three sections could be identified based on the pulse period, which significantly differed between the sections (Kruskal-Wallis: $p<0.0001$; Dunn's multiple-comparisons test, $p<0.0001 ; N=4, n=10$ stimuli/animal).

rates (Fig. 7). In species with short chirps, such as G. bimaculatus and $G$. assimilis, depolarization for $1.6 \mathrm{~s}$ caused the membrane potential of $\mathrm{A} 3-\mathrm{AO}_{\text {bimac }}$ and $\mathrm{A} 3-\mathrm{AO}_{\text {assim }}$ to oscillate continuously in the species-specific pulse pattern accompanied by singing motor activity. Fictive singing activity, however, was not organized in chirps; rather, its duration was determined by the current injection pattern (Fig. $7 A i-B i$ ). In the species with long calling songs, G. rubens and both Teleogryllus species, short current pulses (170 ms in G. rubens and T. oceanicus and $300 \mathrm{~ms}$ in T. commodus) elicited A3-AO membrane potential oscillations during the current injection, accompanied by short bouts of singing motor activity that normally would not occur (Fig. 7Ci-Ei).

In all species tested, the duration of singing episodes was controlled by activation of the A3-AO and the intracellular current pulses set the temporal structure of the singing pattern. Furthermore, in Teleogryllus, the fast and slow sections of the song were induced by long current injection. These data suggest that the normal organization of chirps and trills is not determined just by the A3-AO activity, but also by additional neurons within the network that control and drive the $\mathrm{A} 3-\mathrm{AO}$ interneuron.

\section{Reset of chirp pattern}

In Gryllus species, depolarizing A3-AO with current pulses (4 nA, 100 and $500 \mathrm{~ms}$ duration) during fictive singing modified the ongoing song pattern (Fig. 8). In G. bimaculatus and G. assimilis, the stimulation reset the ongoing chirp rhythm (Fig. $8 A, B$ ). Injection of $100 \mathrm{~ms}$ ( $G$. bimaculatus: $N=5, n=88$; G. assimilis: $N=$ $6, n=97$ ) and $500 \mathrm{~ms}$ ( $G$. bimaculatus: $N=3, n=30$; G. assimilis: $N=6, n=53$ ) pulses at different moments of the chirp cycle revealed a linear relationship between the stimulation phase within the chirp cycle and the shift of the chirp rhythm (Fig. 8Aii-Bii). In G. rubens, there was a linear relationship between the stimulation phase and the shift of the trill rhythm for $500 \mathrm{~ms}$ current pulses ( $N=5, n=62$ trills), but not for the $100 \mathrm{~ms}$ pulses $(N=6, n=86$ trills; Fig. $8 \mathrm{Ci}, \mathrm{Cii})$. In both cases, $r^{2}$ was low, which could be due to the intrinsic variability in the fictive trill pattern in this species. In Teleogryllus species, current injection altered the ongoing singing activity (data not shown); however, the variability of the fictive calling song pattern did not allow us to calculate a reliable phase-response curve.

Response of A3-AO to hyperpolarizing current pulses In G. bimaculatus, hyperpolarizing current injection in the main dendrite of A3-AO demonstrated an after inhibitory rebound that subsequently initiated the generation of singing motor activity (Schöneich and Hedwig, 2012). We analyzed to what degree the A3-AO interneuron of the species shared this property. 
In all five species, injections of $-5 \mathrm{nA}$ pulses for $1 \mathrm{~s}$ in the main dendrite were followed by cycles of depolarization and hyperpolarization accompanied by wingopener and wing-closer motor neuron activity. The rebound depolarization as measured from the resting membrane potential to the peak of the rebound had an amplitude of 3-10 $\mathrm{mV}$ (Fig. 9, vertical arrows) and elicited 1-3 spikes. The subsequent hyperpolarization had an amplitude of $0.5-3 \mathrm{mV}$ (Fig. 9Ai-Ei). However, the shape and amplitude of the elicited depolarization-hyperpolarization cycles were smaller compared with the membrane potential oscillations during fictive singing.

We measured the latency of the first spike generated after release from hyperpolarization by $-0.5 \mathrm{nA}$ to $-10 \mathrm{nA}$ (Fig. 9Aii-Eii, horizontal arrows) and calculated the linear regression functions for the data. In all Gryllus species, the regression functions indicate a tendency for larger-amplitude negative currents inducing longer rebound latencies (Fig. 9Aii-Cii). In $\mathrm{Te}$ leogryllus, data were more variable and a clear tendency cannot be reported (Fig. 9Dii,Eii).

\section{Discussion}

We analyzed the structure and function of the A3-AO neurons in five cricket species that generate different calling songs to reveal if and how species-specific behavior is reflected at the level of an identified CPG interneuron.

The study of neuronal homology across closely related species requires combining different levels of evidence (Weiss and Kupfermann, 1976; Arbas et al., 1991; Katz, 2007, 2016a,b; Niven and Chittka, 2016; Katz and Hale, 2017). Here, we used comprehensive behavioral, neurophysiological, and structural data to reveal the homology of the A3-AO neuron in crickets. Our results suggest that, in all five species, the interneuron can be considered to belong to the singing CPG according to the criteria for identifying CPG components described by Marder and Calabrese (1996).

Neurophysiological evidence for homology of function

The A3-AO interneuron showed similar neurophysiological characteristics across the five species and at least four shared features can be surmised.

First, a ramp depolarization of the membrane potential occurs before the start of chirps or trills. A gradual ramp depolarization of the A3-AO preceded the
A

Gryllus bimaculatus

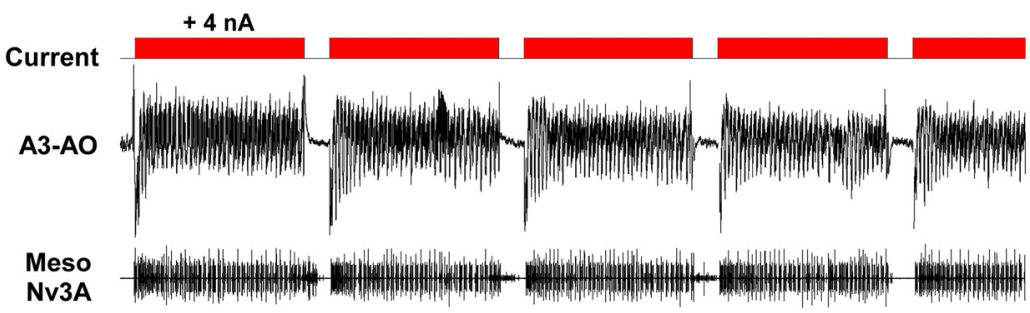

B

Gryllus assimilis

$+4 \mathrm{nA}$

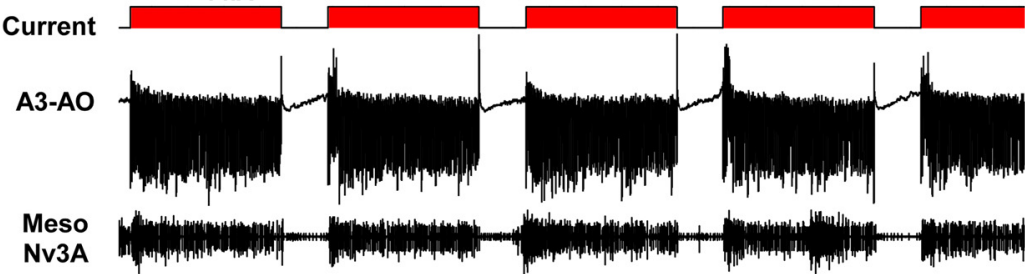

C

Gryllus rubens

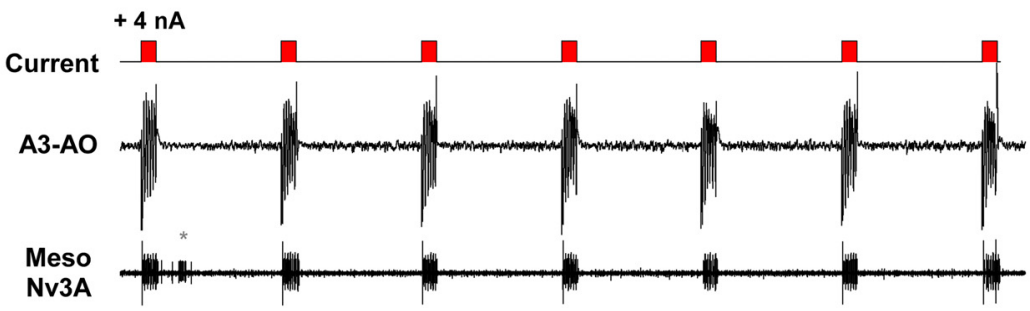

D Teleogryllus commodus

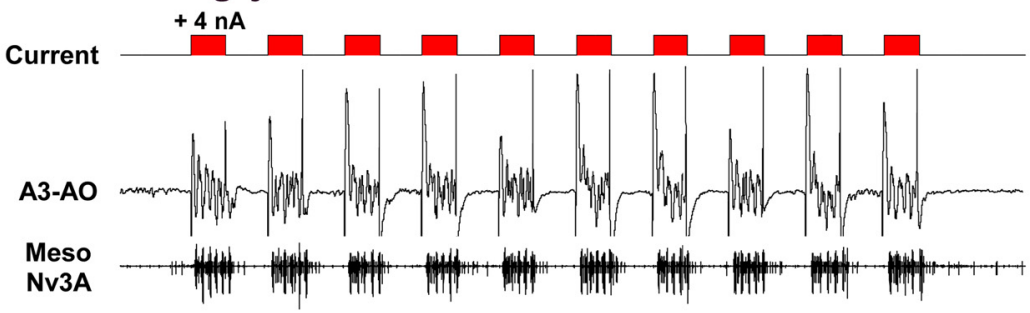

\section{E Teleogryllus oceanicus}

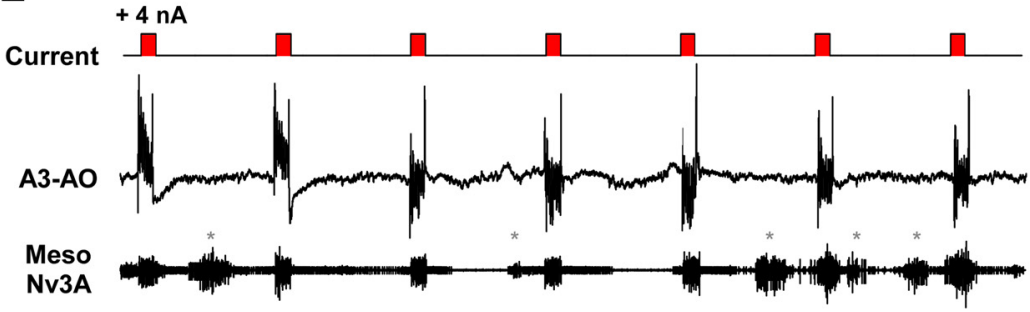

$\left.20 \mathrm{mV}\right|_{1000 \mathrm{~ms}}$

Figure 7. Rhythmic depolarization of $A 3-A 0$ determines temporal structure of singing episodes. $A-E$, Depolarization of $A 3-A 0$ with current pulses of $4 \mathrm{nA}$ (red bar, top trace) elicits rhythmic activity in the interneuron (middle trace) and corresponding fictive singing motor activity (bottom trace). Different current durations were used for the different species. The A3-A0 interneuron is only active for the duration of the current injection. In all five species, the temporal structure of the singing activity is determined by the temporal pattern of the current-imposed A3-A0 activity. In G. rubens and T. oceanicus, motor activity in the meso-NV3A (indicated by gray asterisk) is not related to singing, lacks rhythmicity, is different in amplitude, and the $\mathrm{A} 3-\mathrm{A} 0$ is not active at the same time. 
Ai Gryllus bimaculatus

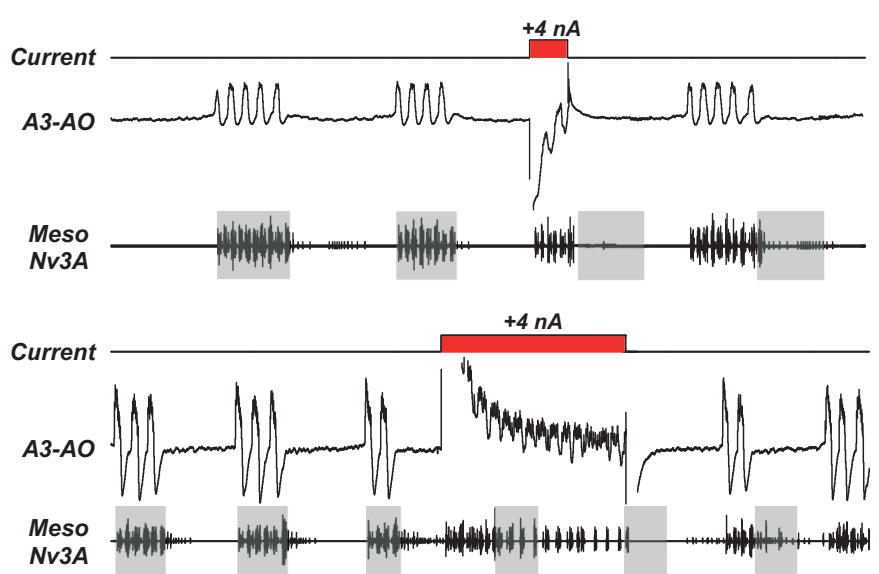

Bi

Gryllus assimilis

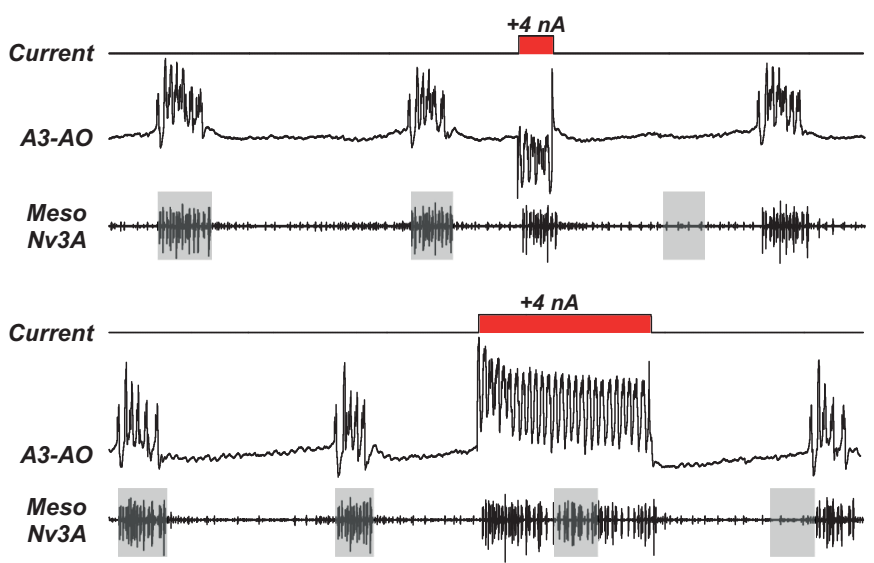

Ci

Gryllus rubens

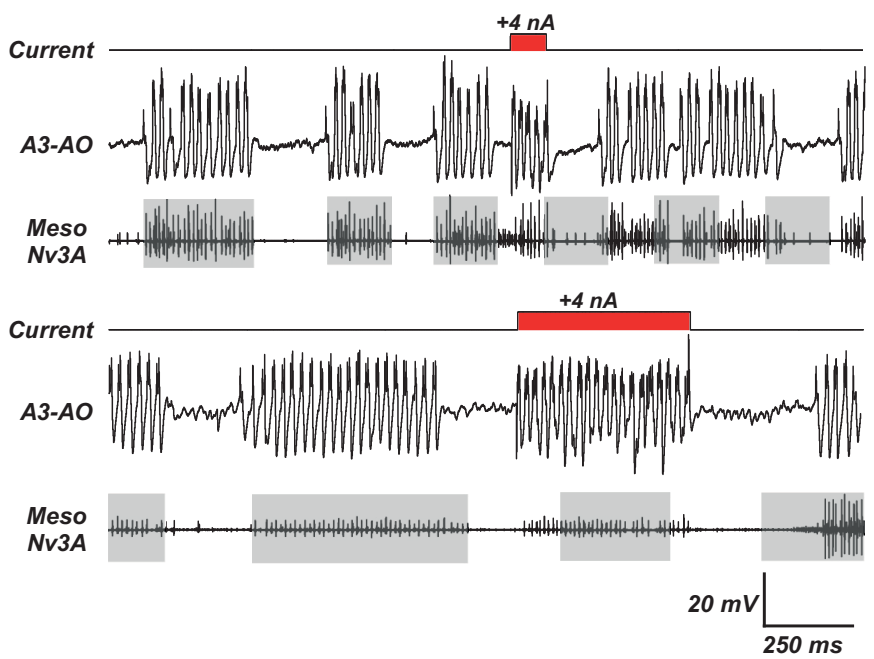

Aii
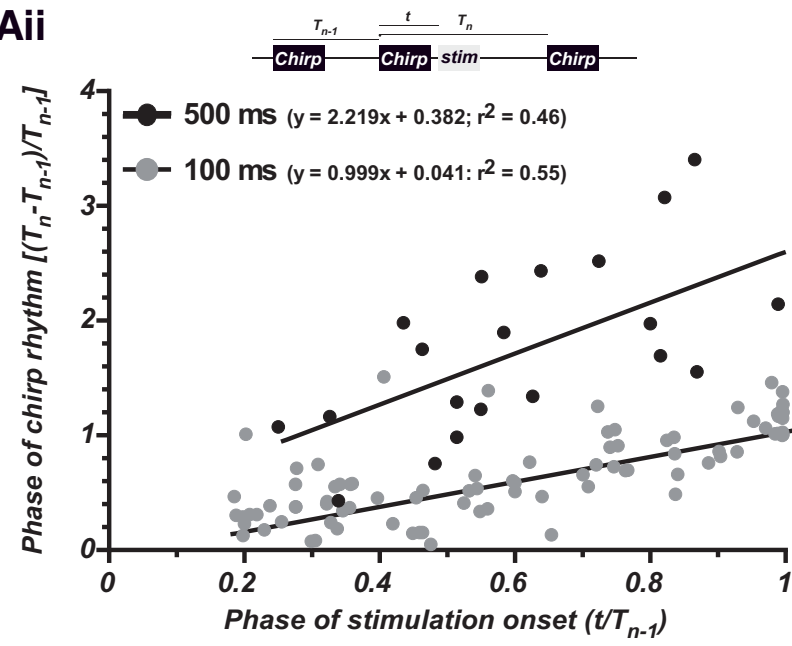

Bii
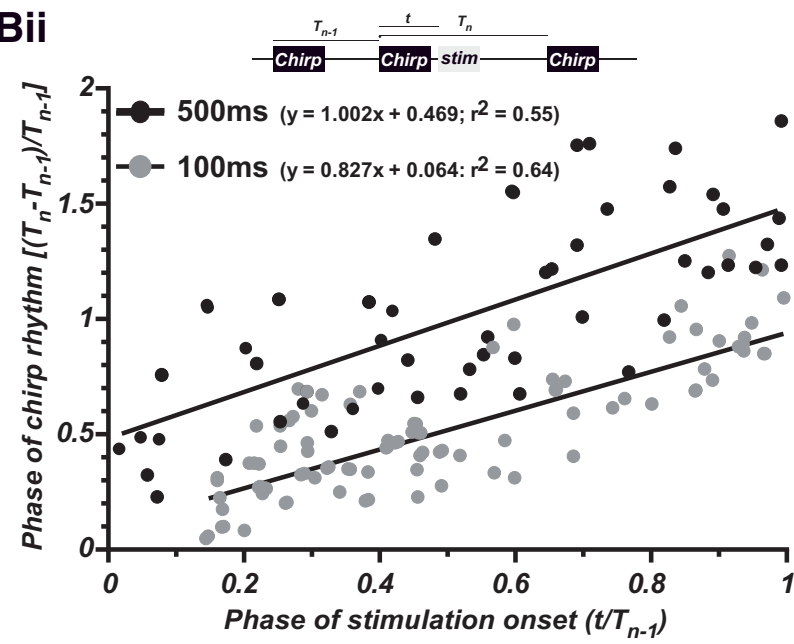

Cii

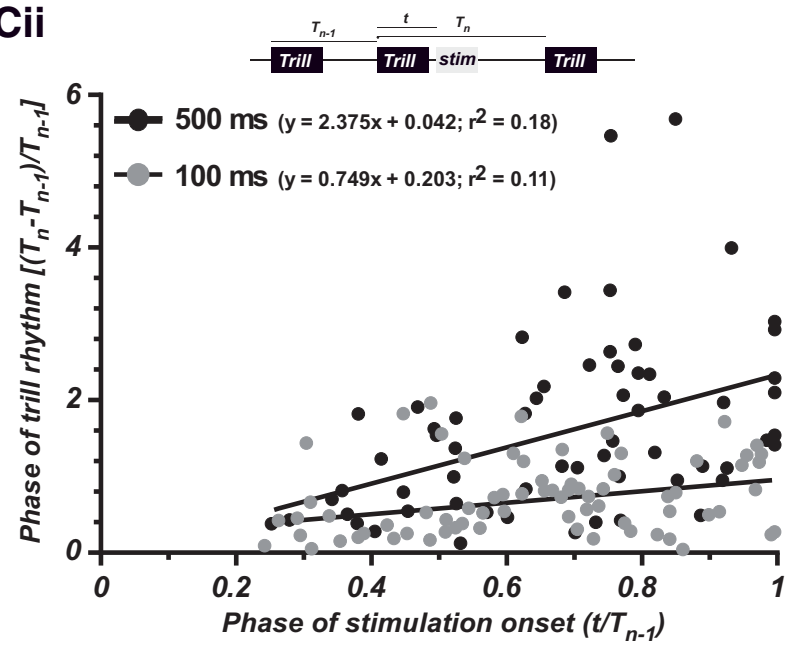

Figure 8. Depolarization of A3-A0 resets the chirp pattern in Gryllus species. Ai-Ci, Reset of Gryllus chirp patterns by depolarizing current injection in A3-A0; 4 nA, 100 or 500 ms. Gray boxes indicate the chirp pattern before stimulation and the predicted subsequent timing. A3-A0 stimulation causes shifts in the chirp activity relative to the expected timing. Concurrent to the current stimulation, a stimulus artifact occurs. Aii-Cii, Phase-response diagrams for current pulses of $100 \mathrm{~ms}$ (gray circles) and $500 \mathrm{~ms}$ (black circles) showing that the shift of the chirp pattern depends linearly on the stimulus phase and current duration except for the $100 \mathrm{~ms}$ current injection in $G$. rubens. Inset, $T_{n-1}$ is the chirp period before stimulation; $t$ is the time from the beginning of the chirp to the time of the current pulse; and $T_{\mathrm{n}}$ is the chirp period after stimulation. 
Ai

\section{Gryllus bimaculatus}

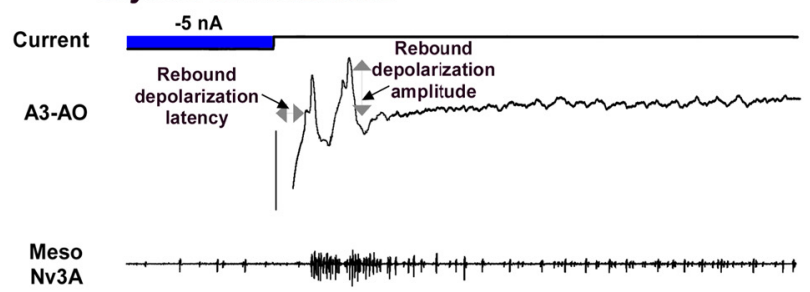

Bi

\section{Gryllus assimilis}

Current

A3-AO

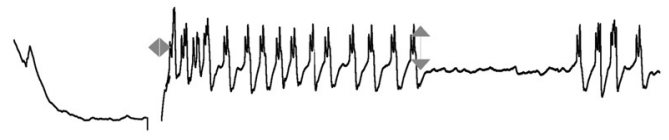

Meso

Nv3A

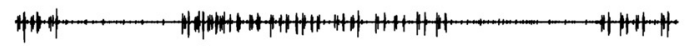

Ci

\section{Gryllus rubens}

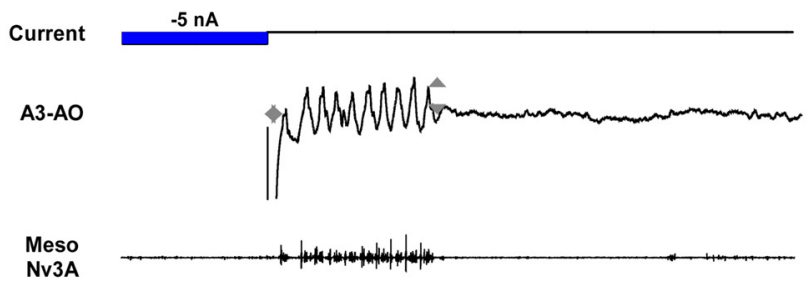

\section{Di}

Teleogryllus commodus

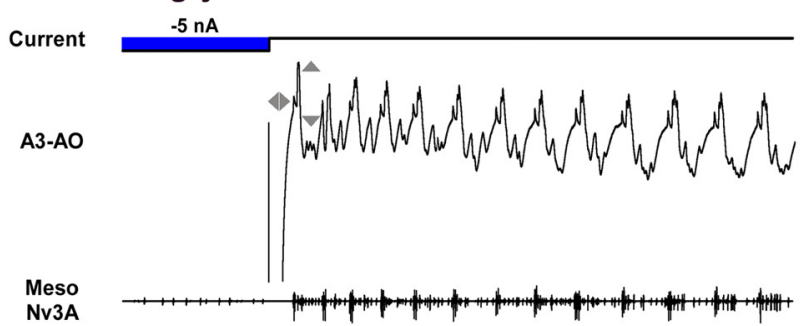

\section{Ei}

Teleogryllus oceanicus

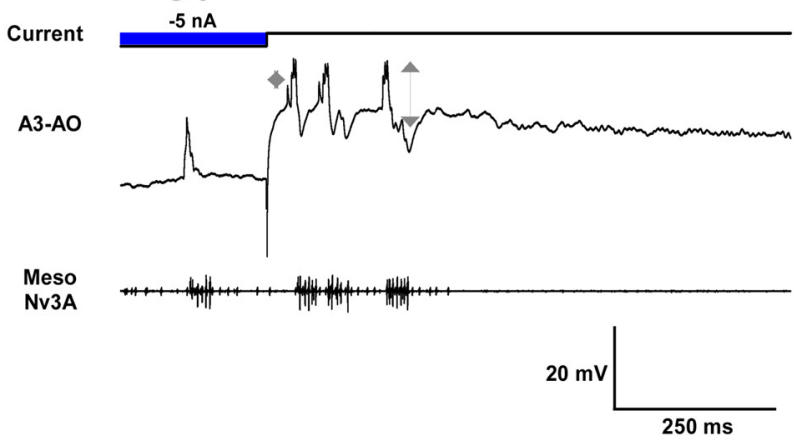

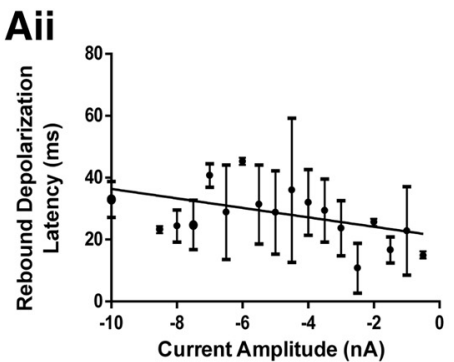

Bii

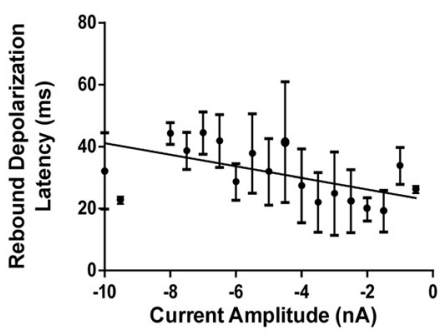

Cii

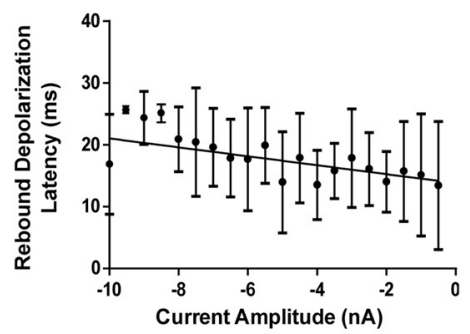

Dii

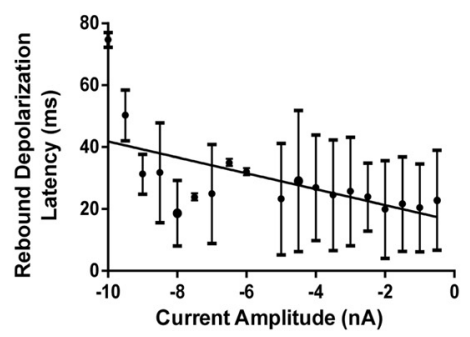

Eii

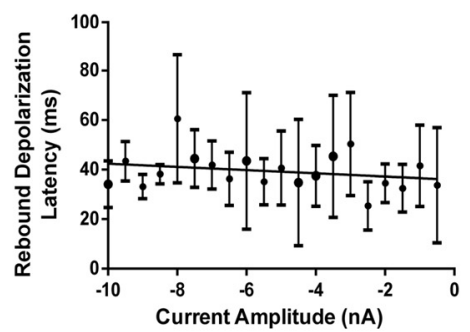

Figure 9. Postinhibitory rebound in A3-A0. Ai-Ei, Hyperpolarization ( $-5 \mathrm{nA}, 1 \mathrm{~s}$; blue bar; top trace) of the A3-A0 (middle trace) was followed by a rebound depolarization and rhythmic membrane potential oscillations with burst spike activity, which elicited rhythmic wing-opener and wing-closer activity (bottom trace). The latency of the rebound depolarization was measured from the end of the current pulse and the first spike of the following depolarization (horizontal arrow). The rebound depolarization amplitude was measured, for each depolarization, from the resting membrane potential and the peak of the depolarization (vertical arrows). Aii-Eii, Latency of the rebound depolarization plotted against different hyperpolarizing current amplitude steps from $-0.5 \mathrm{nA}$ to $-10 \mathrm{nA}$. Latency was determined from the end of the current pulse to the first A3-A0 spike elicited. 
generation of a chirp or trill. This depolarization could be imparted by the descending command neurons, driving the singing CPG with tonic spike activity (Hedwig, 2000) similarly to the swimming CPG in Tritonia (Frost and Katz, 1996). Alternatively, the ramp depolarization may be controlled by neurons of the singing network housed in the posterior ganglia (Jacob and Hedwig, 2016), which control the chirp pattern of the songs.

Second, activity is tightly coupled to the calling song pattern. Depolarization and spike activity precede the wing-opener motoneuron activity followed by a repolarization/hyperpolarization preceding the wing-closer motoneurons. The depolarization and spike burst of A3-AO is always in phase with the wing-opener activity and the hyperpolarization to the wing-closer activity. Additionally, the neurons show species-specific characteristics in terms of the shape of the membrane potential oscillations, the steepness and amplitude of the start of the bursts, and the number of action potentials per depolarization. These differences might be crucial for the timing of the species-specific pulse patterns because the activity of the A3-AO seems to inhibit the closer interneurons during the opener phase. This subsequently triggers the closer interneuron activity (Schöneich and Hedwig, 2012), which drives the closer motoneurons to produce a sound pulse.

At the current level of analysis, it is impossible to reveal to what degree the species-specific characteristics of membrane potential changes are due to intrinsic properties of the A3-AO or due to synaptic inputs driving the neuron. We expect that a combination of specific adaptations of A3-AO conductances and network properties will contribute to the species-specific patterns (Selverston, 1980).

Third, A3-AO is an element of the singing CPG. Its activity elicits the species-specific pulse-pattern of the calling song; in Gryllus it resets the timing of the chirps/trills. Activation of the interneuron by current injection was sufficient to initiate and maintain rhythmic activity of the wing motoneurons typical of the species-specific singing motor pattern and to reset the chirp pattern in the Gryllus species. In Teleogryllus, three significantly different pulse periods occurred upon long current injections. In T. commodus, the structure of the induced motor pattern had a trill-chirp-trill organization and resembled the courtship song (Loher and Rence, 1978; Paripovic et al., 1996). Moreover, stimulation of the neuron with sequences of current injections imposed an artificial song structure in all species. The A3-AO interneuron could be a network element that determines the temporal structure of species-specific song patterns. However, whereas the timing of song episodes is determined by $\mathrm{A} 3-\mathrm{AO}$ activation, the neuron depends on other synaptic inputs from the singing network to organize the chirp/trill pattern and stabilize the normal song pattern. This is consistent with the finding that the A3 ganglion in G. bimaculatus houses part of the pulse-timer network for singing, whereas the temporal pattern of the chirps is controlled by the posterior ganglia (Jacob and Hedwig, 2016).

Fourth, the neuron generates a rebound depolarization after inhibition. The function of the singing CPG is thought to be based on a reciprocal inhibitory network (Bentley, 1969; Schöneich and Hedwig, 2012). The ion channels involved in driving the rebound are not yet identified. Our data show that there is a tendency for the latency of the first spike of the rebound depolarization to become longer with the amplitude of the hyperpolarizing current in the Gryllus species; the effect is quite variable and appears to plateau at $-8 \mathrm{nA}$. Precluding any final conclusion, this might point to the presence of the transient potassium current $I_{\mathrm{A}}$ (Hartline and Gassie, 1979; Harris-Warrick et al., 1995a,b; Pirtle and Satterlie, 2004). These currents are known to be involved in the modulation of the timing of activity of neurons in several motor networks (Tierney and Harris-Warrick, 1992; HarrisWarrick et al., 1995a; Ping et al., 2011). The ion channels involved in driving the rebound will need to be analyzed using voltageclamp and pharmacological experiments.

\section{Structural evidence for homology and functional implications}

Homology based on conserved neuron morphology across species is common and accepted in invertebrate motor systems (Wilson et al., 1982; Arbas, 1983a,b; Schütze and Elsner, 2001) and sensory systems; for example, the Omega-neuron 1 in the auditory pathway of crickets (Casaday and Hoy, 1977; Römer et al., 1988; Stumpner and von Helversen, 2001; Farris et al., 2004). The shared structural features of the A3-AO neuron support homology as the most parsimonious explanation: (1) the conserved position of the cell body located on the posterior ventral side of the A3 ganglion, (2) the location and shape of the extensive anterior dendritic branches and the small posterior dendrites dorsally in $\mathrm{A} 3,(3)$ the axon projection through the most lateral part of the contralateral connective toward the prothoracic ganglion, (4) the axon collaterals present in ganglion T3 and T2, and (5) the dye coupling that reliably occurs between the left-right neurons.

A comparison of the A3-AO structure indicates that its "gestalt" is the same across species, which must be embedded in the species-specific organization of the singing network. The neurons are likely subject to a conserved developmental program, determining the position of the cell body and the shape of the dendritic and axonal ramifications. Specific differences in this program may facilitate the evolution of song patterns. A final proof for homology would require tracing the $\mathrm{A} 3-\mathrm{AO}$ to the same ganglion mother cell (Bate et al., 1981; Pearson et al., 1985).

In Gryllus species, dye coupling revealed that $\mathrm{A} 3-\mathrm{AO}$ neurons are present as one pair of bilateral neurons (Schöneich and Hedwig, 2011, 2012). Our data also support the presence of a single pair of bilateral A3-AO neurons; however, due to the nature of the experiments, the presence of a second pair of $\mathrm{A} 3-\mathrm{AO}$ neurons cannot be excluded. In Teleogryllus, dye coupling demonstrated the existence of at least two pairs of A3-AO neurons and we hypothesize that this might be related to the different song rhythms in Teleogryllus species, pointing to a difference between the clades of Gryllus and Teleogryllus (Huang et al., 2000; Desutter-Grandcolas and Robillard, 2001). The larger number of neurons involved in pattern generation might be a way of increasing the synaptic strength to drive postsynaptic neurons, increasing the reliability of song pattern generation, or allowing more flexibility for the generation of trills and chirps and point to different evolutionary ways to adjust network properties.

Species-specific differences in the dendritic branching pattern may reflect the strength of synaptic connectivity (Macagno et al., 1973; Goodman, 1978; Arbas et al., 1991). Within the singing network, there is clear evidence for species-specific differences in the distribution, size, and density of dendrites and axon collaterals within the neuropil of the A3 and thoracic ganglia, respectively.

\section{Axon collaterals and activity of the $\mathrm{A3}-\mathrm{AO}$ interneuron}

Across all species, the A3-AO neuron showed characteristic projections of its axon collaterals toward the midline of the $\mathrm{T} 3_{\mathrm{A} 1 / \mathrm{A} 2}$ ganglion, which may overlap with descending interneurons of the singing network (Hennig, 1989, 1990; Schöneich and Hedwig, 2012). The arrangement and density of the main axonal collaterals in the $\mathrm{T} 3_{\mathrm{A} 1 / \mathrm{A} 2}$ have characteristic species-specific differences, 
in contrast to the more similar axonal branching pattern in A3 and in T2. The A3-AO axon gives off small collaterals in the dorsal neuropil of the T2 ganglion, which are remarkably similar in the different species. These collaterals could overlap with the dorsal dendrites of the wing-opener motoneurons (Ewing and Hoyle, 1965; Bentley and Kutsch, 1966; Hennig, 1989; Kutsch and Huber, 1989) and A3-AO could be a "premotor" interneuron (Robertson and Pearson, 1983, 1985; Robertson, 1987). Although evidence for synaptic connections has not yet been obtained, in all species, the latency of the A3-AO spike and the wing-opener motoneuron activity, as recorded in meso-Nv3 A, was short and stable. This might be an indicator for a direct link between the A3-AO interneuron and the motoneurons. As at this stage of processing, the pulse pattern is already determined, an A3-AO to motoneuron connection could be a highly conserved part of the singing network with few species-specific adaptations.

\section{Conclusions for species-specific adaptations underlying singing}

In an evolutionary neurobiological approach, significant speciesspecific differences between CPG-networks need to be revealed to understand the evolutionary mechanisms leading to novel motor patterns. Because the fundamental characteristics of the A3-AO are conserved, our data indicate that the fine tuning of cellular and network properties are key to understanding how speciesspecific song patterns emerged. This imposes a fundamental problem of such a network analysis, which will require the combination of neurophysiological and neurogenetic tools to be achieved.

\section{References}

Alexander R (1962) Evolutionary change in cricket acoustical communication. Evolution 16:443-467. CrossRef

Arbas EA (1983a) Thoracic morphology of a flightless mexican grasshopper, Barytettix psolus: comparison with the locust, Schistocerca gregaria. J Morphol 176:141-153. CrossRef Medline

Arbas EA (1983b) Neural correlates of flight loss in a mexican grasshopper, Barytettix psolus. II. DCMD and TCG interneurons. J Comp Neurol 216: 381-389. CrossRef Medline

Arbas EA, Meinertzhagen IA, Shaw SR (1991) Evolution in nervous systems. Annu Rev Neurosci 14:9-38. CrossRef Medline

ASAB Ethics Committee (1997) Guidelines for the treatment of animals in behavioural research and teaching. Anim Behav 53:229-234. CrossRef

Bate M, Goodman CS, Spitzer NC (1981) Embryonic development of identified neurons: segment specific differences in the $\mathrm{H}$ cell homologues. J Neurosci 1:103-106. CrossRef Medline

Bentley DR (1969) Intracellular activity in cricket neurons during generation of song patterns. Z vgl Physiol 283:267-283.

Bentley DR, Hoy RR (1972) Genetic control of the neuronal network generating cricket (Teleogryllus, Gryllus) song patterns. Anim Behav 20:478492. CrossRef Medline

Bentley DR, Kutsch W (1966) The neuromuscular mechanism of stridulation in crickets (Orthoptera: Gryllidae). J Exp Biol 45:151-164. Medline

Blankers T, Block R, Hennig RM (2017) Codivergence but limited covariance of wing shape and calling song structure in field crickets (Gryllus). Evol Biol 45:144-155.

Boughman JW (2002) How sensory drive can promote speciation. Trends Ecol Evol 17:571-577. CrossRef

Capranica RR (1992) The untuning of the tuning curve: is it time? Semin Neurosci 4:401-408. CrossRef

Casaday GB, Hoy RR (1977) Auditory interneurons in the cricket Teleogryllus oceanicus: physiological and anatomical properties. J Comp Physiol A 121:1-13. CrossRef

Chagnaud BP, Baker R, Bass AH (2011) Vocalization frequency and duration are coded in separate hindbrain nuclei. Nat Commun 2:346. CrossRef Medline

Clyne JD, Miesenböck G (2008) Sex-specific control and tuning of the pat- tern generator for courtship song in Drosophila. Cell 133:354-363. CrossRef Medline

Crews D (1997) Species diversity and the evolution of behavioral controlling mechanisms. Ann N Y Acad Sci 807:1-21. CrossRef

Desutter-Grandcolas L, Robillard T (2001) Phylogeny and the evolution of calling songs in Gryllus (Insecta, Orthoptera, Gryllidae). Zool Scr 32:173-183.

Ding Y, Berrocal A, Morita T, Longden KD, Stern DL (2016) Natural courtship song variation caused by an intronic retroelement in an ion channel gene. Nature 536:329-332. CrossRef Medline

Elsner N, Wasser G (1995) The transition from leg to wing stridulation in two geographically distinct populations of the grasshopper Stenobothrus rubicundus. Naturwissenschaften 82:384-386.

Endler JA, Basolo AL (1998) Sensory ecology, receiver biases and sexual selection. Trends Ecol Evol 13:415-420. CrossRef Medline

Ewing A, Hoyle G (1965) Neuronal mechanisms underlying control of sound production in a cricket: Acheta domesticus. J Exp Biol 43:139-153. Medline

Farris HE, Mason AC, Hoy RR (2004) Identified auditory neurons in the cricket Gryllus rubens: temporal processing in calling song sensitive units. Hear Res 193:121-133. CrossRef Medline

Frost WN, Katz PS (1996) Single neuron control over a complex motor program. Proc Natl Acad Sci U S A 93:422-426. CrossRef Medline

Goodman CS (1978) Isogenic grasshoppers: genetic variability in the morphology of identified neurons. J Comp Neurol 182:681-705. CrossRef Medline

Harris-Warrick RM, Coniglio LM, Barazangi N, Guckenheimer J, Gueron S (1995a) Dopamine modulation of transient potassium current evokes phase shifts in a central pattern generator network. J Neurosci 15:342358. CrossRef Medline

Harris-Warrick RM, Coniglio LM, Levini RM, Gueron S, Guckenheimer J (1995b) Dopamine modulation of two subthreshold currents produces phase shifts in activity of an identified motoneuron. J Neurophysiol 74: 1404-1420. CrossRef Medline

Hartline DK, Gassie DV Jr (1979) Pattern generation in the lobster (Panulirus) stomatogastric ganglion: I. Pyloric neuron kinetics and synaptic interactions. Biol Cybern 33:209-222. CrossRef Medline

Hedwig B (2000) Control of cricket stridulation by a command neuron: efficacy depends on the behavioral state. J Neurophysiol 83:712-722. CrossRef Medline

Hennig RM (1989) Neuromuscular activity during stridulation in the cricket Teleogryllus commodus. J Comp Physiol A 165:837-846. CrossRef

Hennig RM (1990) Neuronal control of the forewings in two different behaviours: stridulation and flight in the cricket, Teleogryllus commodus. J Comp Physiol A 167:617-627.

Hoikkala A, Hoy RR, Kaneshiro KY (1989) High-frequency clicks of Hawaiian picture-winged Drosophila species. Anim Behav 37:927-934. CrossRef

Hoikkala A, Kaneshiro KY, Hoy RR (1994) Courtship songs of the picturewinged Drosophila planitibia subgroup species. Anim Behav 47:13631374. CrossRef

Hoy RR, Hoikkala A, Kaneshiro K (1988) Hawaiian courtship songs:evolutionary innovation in communication signals of Drosophila. Science 240: 217-219. CrossRef Medline

Huang Y, Ortí G, Sutherlin M, Duhachek A, Zera A (2000) Phylogenetic relationships of North American field crickets inferred from mitochondrial DNA data. Mol Phylogenet Evol 17:48-57. CrossRef Medline

Jacob PF, Hedwig B (2016) Acoustic signalling for mate attraction in crickets:Abdominal ganglia control the timing of the calling song pattern. Behav Brain Res 309:51-66. CrossRef Medline

Jacob PF, Hedwig B (2015) Impact of cercal air currents on singing motor pattern generation in the cricket (Gryllus bimaculatus DeGeer). J Neurophysiol 114:2649-2660. CrossRef Medline

Kaneshiro KY (1980) Sexual isolation, speciation and the direction of evolution. Evolution 34:437-444. CrossRef Medline

Katz PS (2016a) Evolution of central pattern generators and rhythmic behaviours. Philos Trans R Soc Lond B Biol Sci 371:20150057. CrossRef Medline

Katz PS (2016b) Phylogenetic plasticity in the evolution of molluscan neural circuits. Curr Opin Neurobiol 41:8-16. CrossRef Medline

Katz PS (2007) Evolution and development of neural circuits in invertebrates. Curr Opin Neurobiol 17:59-64. CrossRef Medline

Katz PS, Hale ME (2017) Evolution of motor systems. In: Neurobiology of 
motor control: fundamental concepts and new directions (Hooper SL, Büschges A, eds), pp. 135-176. New York: Wiley.

Katz PS, Harris-Warrick RM (1999) The evolution of neuronal circuits underlying species-specific behavior. Curr Opin Neurobiol 9:628-633. CrossRef Medline

Knepper M, Hedwig B (1997) NEUROLAB, a PC-program for the processing of neurobiological data. Comput Methods Programs Biomed 52:7577. CrossRef Medline

Kutsch W, Huber F (1989) Neural basis of song production. In: Cricket behavior and neurobiology (Huber F, Moore T, Loher W, eds), pp 262309. New York: Cornell University.

Loher W, Rence B (1978) The mating behavior of Teleogryllus commodus (Walker) and its central and peripheral control. Z Tierpsychol 46:225-259.

Macagno ER, Lopresti V, Levinthal C (1973) Structure and development of neuronal connections in isogenic organisms: variations and similarities in the optic system of Daphnia magna. Proc Natl Acad Sci U S A 70:57-61. CrossRef Medline

Marder E, Calabrese RL (1996) Principles of rhythmic motor pattern generation. Physiol Rev 76:687-717. CrossRef Medline

Mendelson TC, Shaw KL (2002) Genetic and behavioral components of the cryptic species boundary between Laupala cerasina and L. kohalensis (Orthoptera: Gryllidae). In: Genetics of mate choice: from sexual selection to sexual isolation (Etges WJ, Noor MAF, eds), pp 301-310. Amsterdam: Springer.

Mendelson TC, Shaw KL (2005) Sexual behaviour: rapid speciation in an arthropod. Nature 433:375-376. CrossRef Medline

Montealegre-Z F, Jonsson T, Robert D (2011) Sound radiation and wing mechanics in stridulating field crickets (Orthoptera: Gryllidae). J Exp Biol 214:2105-2117. CrossRef Medline

Muller HJ (1939) Reversibility in evolution considered from the standpoint of genetics. Biol Rev 14:261-280. CrossRef

Niven JE, Chittka L (2016) Evolving understanding of nervous system evolution. Curr Biol 26:R937-R941. CrossRef Medline

Otte D (1992) Evolution of cricket songs. J Orthoptera Res 1:25-49.

Paripovic I, Hennig RM, Otto D (1996) Abdominal ventilatory pattern in crickets depends on the stridulatory motor pattern. Physiol Entomol 21: 223-230. CrossRef

Pearson KG, Boyan GS, Bastiani M, Goodman CS (1985) Heterogeneous properties of segmentally homologous interneurones in the ventral cord of locusts. J Comp Neurol 233:133-145. CrossRef Medline

Ping Y, Waro G, Licursi A, Smith S, Vo-Ba DA, Tsunoda S (2011) Shal/Kv4 channels are required for maintaining excitability during repetitive firing and normal locomotion in Drosophila. PLoS One 6:e16043. CrossRef Medline

Pirtle TJ, Satterlie RA (2004) Cellular mechanisms underlying swim acceleration in the pteropod mollusc Clione limacina. Integr Comp Biol 44: 37-46. CrossRef Medline

Poulet JF, Hedwig B (2003) A corollary discharge mechanism modulates central auditory processing in singing crickets. J Neurophysiol 89:15281540. CrossRef Medline

Ritchie MG (2007) Sexual selection and speciation. Annu Rev Ecol Evol Syst 38:79-102. CrossRef

Robertson RM (1987) Interneurons in the flight system of the cricket Teleogryllus oceanicus. J Comp Physiol A 160:431-445. CrossRef

Robertson RM, Pearson KG (1983) Interneurons in the flight system of the locust: distribution, connections, and resetting properties. J Comp Neurol 215:33-50. CrossRef Medline

Robertson RM, Pearson KG (1985) Neural circuits in the flight system of the locust. J Neurophysiol 53:110-128. CrossRef Medline

Römer H, Marquart V, Hardt M (1988) Organization of a sensory neuropile in the auditory pathway of two groups of Orthoptera. J Comp Neurol 275:201-215. CrossRef Medline

Schöneich S, Hedwig B (2012) Cellular basis for singing motor pattern generation in the field cricket (Gryllus bimaculatus DeGeer). Brain Behav 2:707-725. CrossRef Medline

Schöneich S, Hedwig B (2011) Neural basis of singing in crickets:central pattern generation in abdominal ganglia. Naturwissenschaften 98:1069_ 1073. CrossRef Medline

Schöneich S, Schildberger K, Stevenson PA (2011) Neuronal organization of a fast-mediating cephalothoracic pathway for antennal-tactile information in the cricket (Gryllus bimaculatus DeGeer). J Comp Neurol 519: 1677-1690. CrossRef Medline

Schütze H, Elsner N (2001) Stridulatory pattern generation in acridid grasshoppers: metathoracic interneurons in Stenobothrus rubicundus (Germar, 1817). J Comp Physiol A 187:529-540. CrossRef Medline

Selverston AI (1980) Are central pattern generators understandable? Behav Brain Sci 3:535-571. CrossRef

Shaw KL (1996) Polygenic inheritance of a behavioral phenotype:interspecific genetics of song in the Hawaiian cricket genus Laupala. Evolution 50:256-266. CrossRef Medline

Shirangi TR, Stern DL, Truman JW (2013) Motor control of Drosophila courtship song. Cell Rep 5:678-686. CrossRef Medline

Stumpner A, von Helversen D (2001) Evolution and function of auditory systems in insects. Naturwissenschaften 88:159-170. CrossRef Medline

ter Hofstede HM, Schöneich S, Robillard T, Hedwig B (2015) Evolution of a communication system by sensory exploitation of startle behavior. Curr Biol 25:3245-3252. CrossRef Medline

Tierney AJ, Harris-Warrick RM (1992) Physiological role of the transient potassium current in the pyloric circuit of the lobster stomatogastric ganglion. J Neurophysiol 67:599-609. CrossRef Medline

Vedenina V, Fähsing S, Sradnick J, Klöpfel A, Elsner N (2012) A narrow hybrid zone between the grasshoppers Stenobothrus clavatus and Stenobothrus rubicundus (Orthoptera:Gomphocerinae): female preferences for courtship songs. Biol J Linn Soc 107:383-397. CrossRef

von Philipsborn AC, Jörchel S, Tirian L, Demir E, Morita T, Stern DL, Dickson BJ (2014) Cellular and behavioral functions of fruitless isoforms in Drosophila courtship. Curr Biol 24:242-251. CrossRef Medline

von Philipsborn AC, Liu T, Yu JY, Masser C, Bidaye SS, Dickson BJ (2011) Neuronal control of Drosophila courtship song. Neuron 69:509-522. CrossRef Medline

Weiss KR, Kupfermann I (1976) Homology of the giant serotonergic neurons (metacerebral cells) in Aplysia and pulmonate molluscs. Brain Res 117:33-49. CrossRef Medline

Wenzel B, Hedwig B (1999) Neurochemical control of cricket stridulation revealed by pharmacological microinjections into the brain. J Exp Biol 202:2203-2216. Medline

Wilson JA, Phillips CE, Adams ME, Huber F (1982) Structural comparison of a homologous neuron in Gryllid and Acridid insects. J Neurobiol 13: 459-467. CrossRef Medline 